\title{
An experimental study of amphibole stability in low-pressure granitic magmas and a revised $\mathrm{Al}$-in-hornblende geobarometer
}

\author{
E. J. F. Mutch ${ }^{1,3}$ - J. D. Blundy ${ }^{1,2}$ • B. C. Tattitch ${ }^{1}$ F. J. Cooper ${ }^{1}$ R. A. Brooker ${ }^{1}$
}

Received: 17 March 2016 / Accepted: 7 September 2016 / Published online: 24 September 2016

(C) The Author(s) 2016. This article is published with open access at Springerlink.com

\begin{abstract}
We report new experimental data on the composition of magmatic amphiboles synthesised from a variety of granite (sensu lato) bulk compositions at near-solidus temperatures and pressures of $0.8-10 \mathrm{kbar}$. The total aluminium content $\left(\mathrm{Al}^{\text {tot }}\right)$ of the synthetic calcic amphiboles varies systematically with pressure $(P)$, although the relationship is nonlinear at low pressures $(<2.5 \mathrm{kbar})$. At higher pressures, the relationship resembles that of other experimental studies, which suggests of a general relationship between $\mathrm{Al}^{\text {tot }}$ and $\mathrm{P}$ that is relatively insensitive to bulk composition. We have developed a new Al-in-hornblende geobarometer that is applicable to granitic rocks with the low-variance mineral assemblage: amphibole + plagioclase $\left(\mathrm{An}_{15-80}\right)+$ biotite + quartz + alkali feldspar + ilmenite/ titanite + magnetite + apatite. Amphibole analyses should be taken from the rims of grains, in contact with plagioclase and in apparent textural equilibrium with the rest of the mineral assemblage at temperatures close to the haplogranite solidus $\left(725 \pm 75^{\circ} \mathrm{C}\right)$, as determined from amphibole-plagioclase thermometry. Mean amphibole rim compositions that meet these criteria can then be used to calculate $P$ (in kbar) from $\mathrm{Al}^{\text {tot }}$ (in atoms per formula unit, apfu) according to the expression:
\end{abstract}

Communicated by Gordon Moore, Ph.D.

E. J. F. Mutch

ejfm2@cam.ac.uk

1 School of Earth Sciences, University of Bristol, Wills Memorial Building, Bristol BS8 1RJ, UK

2 Division of Geological and Planetary Sciences, California Institute of Technology, 1200 E. California Blvd, Pasadena, CA 91125, USA

3 Department of Earth Sciences, University of Cambridge, Downing Street, Cambridge CB2 3EQ, UK
$P(\mathrm{kbar})=0.5+0.331(8) \times \mathrm{Al}^{\mathrm{tot}}+0.995(4) \times\left(\mathrm{Al}^{\mathrm{tot}}\right)^{2}$

This expression recovers equilibration pressures of our calibrant dataset, comprising both new and published experimental and natural data, to within $\pm 16 \%$ relative uncertainty. An uncertainty of $10 \%$ relative for a typical $\mathrm{Al}^{\text {tot }}$ value of 1.5 apfu translates to an uncertainty in pressure estimate of $0.5 \mathrm{kbar}$, or $15 \%$ relative. Thus the accuracy of the barometer expression is comparable to the precision with which near-solidus amphibole rim composition can be characterised.

Keywords Granitoid geobarometry $\cdot$ Al-in-hornblende · Amphibole stability · Phase-equilibria experiments

\section{Introduction}

Plutons of broadly granitic (or "granitoid") composition are widespread in the continental crust and play an important role in the evolution of orogenic terranes. Consequently, dated plutons of known emplacement depth can be used as 'crustal nails' to track complex crustal exhumation during orogenesis (Anderson 1996; Ague and Brimhall 1988b). Granitoid plutons also have close associations with hydrothermal ore deposits, notably porphyry copper deposits (PCDs) that are the world's primary source of $\mathrm{Cu}$ and $\mathrm{Mo}$ (Sillitoe 2010). Granitoid bodies are predominantly found in the upper continental crust $(2-20 \mathrm{~km})$, with mineralised porphyry stocks occupying the shallow limit of this range $(\leq 4 \mathrm{~km})$. However, providing an accurate quantitative constraint on the emplacement depth of individual intrusions, particularly at the shallow crustal depths that typify many ore-related plutons, has proven difficult (Anderson et al. 2008). Evidently granite geobarometry is an important 
tool for solving problems in both tectonics and economic geology.

Pluton emplacement depth (pressure) estimates can be retrieved from adjacent metamorphic aureoles containing appropriate mineral assemblages for barometric calculations (Anderson et al. 2008). However, suitable aureole assemblages are relatively rare, especially in calcareous country rocks, quartzofeldspathic rocks (e.g. metagranitoids) or other alumina-poor sediments, lacking aluminosilicate porphyroblasts (Ague 1997). Moreover, this method of estimating emplacement pressure can be compromised by extensive overprinting and relative motion between the pluton and the surrounding wall rocks during magma ascent (Zen 1989). What would be preferable is a means of recovering pressure from the solidified plutonic rocks themselves.

Calcic amphibole is a common solid-solution mineral in intermediate and felsic rocks; its composition is sensitive to pressure, temperature and bulk composition, making it a potentially useful phase for estimating directly the conditions under which evolved magmas crystallised. Creating a general amphibole thermobarometer that is applicable to a wide range of igneous systems has been fraught with challenges (Putirka 2016; Erdmann et al. 2014). This is particularly true for high-temperature volcanic systems $\left(>800^{\circ} \mathrm{C}\right)$ that have high thermodynamic variance where the equilibria that control element partitioning into amphibole are still poorly understood (Putirka 2016). In near-solidus, low variance granitoid systems, however, the total aluminium content ( $\mathrm{Al}^{\text {tot }}$ atoms per formula unit) of igneous hornblende is known to be particularly sensitive to intensive parameters through a combination of the pressure-sensitive Tschermak exchanges (Eqs. 1a, 1b) and the temperature-sensitive edenite exchange (Eq. 2) (Hollister et al. 1987; Blundy and Holland 1990).

Tremolite + Phlogopite +2 Albite +2 Anorthite

$=2$ Pargasite +6 Quartz + Orthoclase

Phlogopite + 2 Quartz + 2 Anorthite

$=$ Tschermakite + Orthoclase

Tremolite + Albite $=$ Edenite +4 Quartz

The second of these equilibria is the basis of the widely used amphibole-plagioclase geothermometer of Holland and Blundy (1994). Equilibrium (1), which involves, in addition to amphibole, plagioclase and quartz, the common granite minerals biotite and alkali feldspar, was explored as a geobarometer by Ague (1997), using thermodynamic data for the various mineral end-members. Although his barometer has considerable potential, the slope of the reaction in $P-T$ space is small $(\mathrm{d} P / \mathrm{d} T \approx 13 \mathrm{bar} / \mathrm{K})$ and Equilibrium (1) must be used in conjunction with the Holland and Blundy (1994) thermometer to yield pressures. More recently, Ridolfi et al. (2010) and Ridolfi and Renzulli (2012) have used total Al content of experimental amphiboles from a variety of starting materials in the pressure range 1.3-22 kbar to formulate a barometer. Their formulation does not stipulate a particular buffering assemblage, so it is unclear what reaction(s) controls the barometer expressions that they provide.

An alternative, and pragmatic, approach to amphibole barometry in granitic rocks, based around Equilibrium (1), was proposed by Hammarstrom and Zen (1986). They argued that although Equilibrium (1) ultimately controls the $\mathrm{Al}$ content of magmatic hornblende, the low thermodynamic variance of granitic systems at or close to the solidus means that additional influences on amphibole Al content, such as temperature and bulk composition, are minimised. They argued that in an 11-component granitic system $\left(\mathrm{SiO}_{2}-\mathrm{Al}_{2} \mathrm{O}_{3}-\mathrm{TiO}_{2}-\mathrm{FeO}-\mathrm{Fe}_{2} \mathrm{O}_{3}-\mathrm{MgO}-\mathrm{CaO}-\mathrm{Na}_{2} \mathrm{O}-\mathrm{K}_{2} \mathrm{O}-\right.$ $\mathrm{P}_{2} \mathrm{O}_{5}-\mathrm{H}_{2} \mathrm{O}$ ) containing the ten phases amphibole + biotite + plagioclase $\left(\mathrm{An}_{10}{ }^{-}{ }_{50}\right)+$ quartz $+\mathrm{K}$-feldspar + magnetite + ilmenite (or titanite) + apatite + melt $+\mathrm{H}_{2} \mathrm{O}$-rich vapour, the thermodynamic variance is equal to 3 . As most calc-alkaline plutons exhibit a redox state close to the nickel-bunsenite (NNO) buffer and the water-saturated haplogranite solidus is approximately isothermal above 2.5 kbar (Holtz and Johannes 1994; Johannes and Holtz 1996), all of the chemical variation can be ascribed to a single intensive variable, pressure. The predominant chemical variable in this situation is the $\mathrm{Al}$ content of amphibole, which they argued would provide for a solidus barometer in hornblende-bearing granites, provided that it could be demonstrated that the low-variance mineral assemblage was in equilibrium. The use of a slow-diffusing element like $\mathrm{Al}$ tends to limit any subsolidus redistribution and reduce the susceptibility of the barometer to being reset.

This approach has been explored several times using either natural plutons with independent depth estimates (Hammarstrom and Zen 1986; Hollister et al. 1987) or high pressure and temperature phase-equilibria experiments employing a variety of techniques and starting materials (Johnson and Rutherford 1989; Thomas and Ernst 1990; Schmidt 1992). In each case, the Al content of amphibole was found to correlate linearly with pressure within the calibrated pressure range of 2-14 kbar (Table 1).

The three experimental calibrations claim significantly smaller uncertainties than the original Hammarstrom and Zen (1986) calibration. However, the variation from one calibration to another means that, for a typical granitic amphibole $\mathrm{Al}^{\text {tot }}$ content of $1.5 \mathrm{apfu}$, the calculated pressure may vary from 1.8 to $4.1 \mathrm{kbar}$, greatly exceeding the apparent precision of any individual experimental study. These differences were variously ascribed to: the nature of the fluid phase $\left(\mathrm{H}_{2} \mathrm{O}\right.$ versus $\mathrm{H}_{2} \mathrm{O}-\mathrm{CO}_{2}$ mixtures $)$, the 
Table 1 Regression parameters of previous calibrations of the Al-inhornblende barometer of the form $P=a \cdot \mathrm{Al}^{\text {tot }}+b$. H\&Z (1986) is Hammarstrom and Zen (1986); J\&R (1989) is Johnson and Rutherford (1989); T\&E (1990) is Thomas and Ernst (1990)

\begin{tabular}{lllll}
\hline References & $a$ & $b$ & $\begin{array}{l}\text { Uncertainty } \\
\text { (kbar) }\end{array}$ & $R^{2}$ \\
\hline H\&Z (1986) & 5.03 & -3.92 & 3.0 & 0.80 \\
Hollister et al. (1987) & 5.64 & -4.76 & 1.0 & 0.97 \\
J\&R (1989) & 4.23 & -3.46 & 0.5 & 0.99 \\
T\&E (1990) & 5.34 & -6.23 & 1.0 & 0.94 \\
Schmidt (1992) & 4.76 & -3.01 & 0.6 & 0.99 \\
\hline
\end{tabular}

experimental technique (amphibole is notoriously reluctant to produce large crystals in near-solid experiments and seed crystals were normally required), the experimental temperature (from 10 to $100{ }^{\circ} \mathrm{C}$ above the water-saturated granite solidus) or the experimental bulk composition (from tonalite to granodiorite). The issue of fluid composition was considered particularly important because of the well-known effect of dissolved $\mathrm{CO}_{2}$ in the fluid to raise the solidus temperature, e.g. by $50{ }^{\circ} \mathrm{C}$ from $\mathrm{XH}_{2} \mathrm{O}=1$ to $\mathrm{XH}_{2} \mathrm{O}=0.75$ (Keppler 1989). Anderson and Smith (1995) attempted to address the issue of temperature dependence by combining the higher-temperature, mixed $\mathrm{H}_{2} \mathrm{O}-\mathrm{CO}_{2}$ fluid experiments of Johnson and Rutherford (1989) with the lower temperature, pure $\mathrm{H}_{2} \mathrm{O}$ experiments of Schmidt (1992) to produce a thermobarometer that took account simultaneously of temperature and pressure of amphibole crystallisation. Their formulation also claims an accuracy of the order 0.6 kbar provided that the crystallisation temperature is known accurately. For example, uncertainty of $\pm 50{ }^{\circ} \mathrm{C}$ in amphibole crystallisation temperature equates to a pressure variation of more than $\pm 0.6 \mathrm{kbar}$ for an $\mathrm{Al}^{\text {tot }}$ of 1.5.

Despite the obvious difficulty in creating a robust igneous amphibole barometer that is applicable across a wide range of bulk compositions, the use of the existing formulations, most notably that of Schmidt (1992), has been remarkably widespread, as it often provides the only reliable means of constraining the pressure (depth) at which a granitic pluton was emplaced and solidified. A number of problems remain, however:

1. Many plutons are emplaced at pressures below $2.5 \mathrm{kbar}$ where the haplogranite solidus increases sharply in temperature, e.g. by $45{ }^{\circ} \mathrm{C}$ from 2.5 to $1.0 \mathrm{kbar}$ (Johannes and Holtz 1996). It is unclear what effect such an increase in temperature will have on amphibole $\mathrm{Al}^{\text {tot }}$ in the low-variance assemblage

2. The bulk chemistry of calc-alkaline plutonic rocks varies widely, notably in their alumina content. All of the starting materials used for calibration experiments have $\mathrm{Al}_{2} \mathrm{O}_{3}$ contents above $16 \mathrm{wt} \%$, yet many natural amphibole-bearing granites have less than this value. What effect does the activity of $\mathrm{Al}_{2} \mathrm{O}_{3}$ in the melt, and that of other components, have on the barometer calibrations?

3. The barometer relies on using the $\mathrm{Al}$ content of amphibole that crystallised at the granite solidus, not above during emplacement, nor below during subsolidus reequilibration. How reliable are textural criteria for the identification of such amphiboles and what effect does this uncertainty has on estimated pressures?

4. Amphiboles in igneous rocks are typically zoned. Even when textural evidence for amphibole growth at the solidus is compelling, the standard deviation of $\mathrm{Al}^{\text {tot }}$ contents is rarely less than 0.15 apfu. Given that the relationship between pressure and $\mathrm{Al}^{\text {tot }}$ involves a slope of $\sim 5$, the propagated uncertainty in pressure that accrues from variability in $\mathrm{Al}^{\text {tot }}$ is comparable in magnitude to the accuracy of the barometers. What, then, are realistic upper limits on barometer accuracy and precision?

5. To be reliable the barometer requires a buffer assemblage of 11 phases to be at, or close to, saturation. If the amphibole in question did not achieve equilibrium with one or two of these phases what effect will this have on pressure estimates?

6. All of the existing barometer calibrations have negative intercepts on the pressure axis at zero $\mathrm{Al}$ apfu. This is untenable, not least because the minimum pressure at which amphibole can crystallise from a granitic melt is thought to be around $0.5 \mathrm{kbar}$ (Sato et al. 1999). How reliable is the barometer at low pressure, especially when the lowest pressure of barometer calibration is 2 kbar?

The aim of this study is to address the above concerns regarding the extant $\mathrm{Al}$-in-hornblende barometers by performing phase equilibrium experiments on a range of lower $\mathrm{Al}_{2} \mathrm{O}_{3}$ starting materials, at pressures of 10 down to $0.8 \mathrm{kbar}$ and over a range of near-solidus temperatures. The resulting amphibole analyses are used in conjunction with a wider dataset, experimental and natural, to test the validity of the assumptions inherent in the barometer and provide a revised calibration that is applicable down to the minimum pressures at which amphibole crystallises.

\section{Methods and materials}

\section{Starting materials}

We selected three different bulk compositions to represent a range of typical orogenic granites, and to extend 
Table 2 Starting materials

\begin{tabular}{|c|c|c|c|c|c|c|c|}
\hline \multirow[t]{3}{*}{ Whole rock } & \multicolumn{3}{|l|}{ This study } & \multirow[t]{2}{*}{ J\&R (1989) } & \multirow[t]{2}{*}{ T\&E (1990) } & \multicolumn{2}{|c|}{ Schmidt (1992) } \\
\hline & MC1314 & FSC1332 & CMA & & & REF-PR & AU7 \\
\hline & Tonalite & Granodiorite & Rhyolite & Dacite & Tonalite & Tonalite & Granodiorite \\
\hline Latitude & $18.4618^{\circ} \mathrm{S}$ & $22.7201^{\circ} \mathrm{S}$ & $18.1864^{\circ} \mathrm{S}$ & - & - & - & - \\
\hline Longitude & $69.7977^{\circ} \mathrm{W}$ & $69.2137^{\circ} \mathrm{W}$ & $69.7628^{\circ} \mathrm{W}$ & - & - & - & - \\
\hline $\mathrm{SiO}_{2}$ & 59.56 & 71.96 & 76.29 & 64.63 & 57.69 & 60.02 & 68.03 \\
\hline $\mathrm{TiO}_{2}$ & 1.15 & 0.45 & 0.00 & 0.60 & 0.70 & 0.72 & 0.41 \\
\hline $\mathrm{Al}_{2} \mathrm{O}_{3}$ & 14.72 & 13.19 & 13.16 & 17.04 & 18.32 & 17.11 & 16.25 \\
\hline $\mathrm{Fe}_{2} \mathrm{O}_{3}$ & 9.25 & 3.73 & 0.60 & 4.75 & 6.60 & 6.65 & 3.72 \\
\hline $\mathrm{MnO}$ & 0.14 & 0.07 & 0.00 & 0.11 & 0.11 & 0.11 & 0.11 \\
\hline $\mathrm{MgO}$ & 3.54 & 1.16 & 0.00 & 1.11 & 3.18 & 3.21 & 1.61 \\
\hline $\mathrm{CaO}$ & 6.43 & 3.08 & 2.25 & 3.63 & 6.37 & 6.60 & 4.52 \\
\hline $\mathrm{Na}_{2} \mathrm{O}$ & 2.74 & 3.54 & 2.78 & 4.05 & 3.53 & 2.88 & 2.54 \\
\hline $\mathrm{K}_{2} \mathrm{O}$ & 2.12 & 2.70 & 4.92 & 4.07 & 3.12 & 2.46 & 2.68 \\
\hline $\mathrm{P}_{2} \mathrm{O}_{5}$ & 0.34 & 0.13 & 0.00 & 0.00 & 0.37 & 0.23 & 0.12 \\
\hline \multicolumn{8}{|l|}{ Amphibole } \\
\hline $\mathrm{SiO}_{2}$ & 46.81 & 46.48 & - & - & - & - & - \\
\hline $\mathrm{TiO}_{2}$ & 1.12 & 1.42 & - & - & - & - & - \\
\hline $\mathrm{Al}_{2} \mathrm{O}_{3}$ & 5.76 & 7.04 & - & - & - & - & - \\
\hline $\mathrm{Cr}_{2} \mathrm{O}_{3}$ & 0.00 & 0.00 & - & - & - & - & - \\
\hline $\mathrm{FeO}$ & 19.38 & 15.12 & - & - & - & - & - \\
\hline $\mathrm{MnO}$ & 0.36 & 0.36 & - & - & - & - & - \\
\hline $\mathrm{MgO}$ & 10.75 & 13.35 & - & - & - & - & - \\
\hline $\mathrm{CaO}$ & 10.88 & 11.07 & - & - & - & - & - \\
\hline $\mathrm{Na}_{2} \mathrm{O}$ & 1.28 & 1.75 & - & - & - & - & - \\
\hline $\mathrm{K}_{2} \mathrm{O}$ & 0.61 & 0.71 & - & - & - & - & - \\
\hline $\mathrm{Cl}$ & 0.38 & 0.29 & - & - & - & - & - \\
\hline Total & 97.33 & 97.60 & - & - & - & - & - \\
\hline \multicolumn{8}{|c|}{ Plagioclase (rim) } \\
\hline Anorthite & 0.30 & 0.38 & - & - & - & - & - \\
\hline
\end{tabular}

Experimental starting materials from this study and previous experimental calibrations

T\&E is Thomas and Ernst

$\mathrm{J} \& \mathrm{R}$ is Johnson and Rutherford

the experimental starting materials of previous studies to lower bulk $\mathrm{Al}_{2} \mathrm{O}_{3}$ contents. Our starting materials, all from locations in northern Chile, are: a tonalite from the Cretaceous Lluta Batholith (MC1314); a Cretaceous granodiorite from west of Calama, close to the Spence copper mine (FSC1332), and a rhyolite pumice from the Miocene Cardones Ignimbrite (CMA; van Zalinge et al. in press). Bulk compositions and locations of these starting materials are given in Table 2, along with compositions from the experimental studies of Johnson and Rutherford (1989), Thomas and Ernst (1990) and Schmidt (1992) for comparison. How these bulk compositions compare to compositional variation observed in natural granitoids is illustrated in Fig. 1.

We adopted three strategies for preparation of starting materials; this was in an attempt to approach the same end result from different starting points, although we recognise that this approach does not constitute a reversal in the formal sense. The first series of experiments used a coarsely crushed powder (cf. Pichavant et al. 2007) of MC1314 ( $>30 \mu \mathrm{m}$ grain size); the second series used a finely crushed $(<30 \mu \mathrm{m})$ powder of MC1314 or CMA; the third series used starting materials of MC1314 or FSC1332, fused with excess $\mathrm{H}_{2} \mathrm{O}$ in a TZM pressure vessel (see below) to create a water-saturated glass. We did not seed any of the starting materials with hornblende, in contrast to the experimental studies of Thomas and Ernst (1990) and Schmidt (1992). Samples MC1314 and FSC1332 contain primary magmatic hornblende; its composition, as well as that of the coexisting plagioclase rims, is given in Table 2. MC1314 shows signs of incipient propylitic alteration, whereas FSC1332 
Fig. 1 Chemical variation of experimental starting materials used in this study and from other barometer calibrations that used either experiments or natural granitoids. All compositions are given in Table 2. Natural data from Ague and Brimhall (1988a) and Dilles (1987) are also presented in addition to 4907 analyses of natural granitoids (granites, granodiorites, tonalites) from the GEOROC database (grey dots). a $\mathrm{SiO}_{2}$ versus $\mathrm{Al}_{2} \mathrm{O}_{3}, \mathbf{b ~} \mathrm{Na}_{2} \mathrm{O}$ versus $\mathrm{K}_{2} \mathrm{O}$, c $\mathrm{FeO}_{\text {total }}$ versus $\mathrm{CaO}$. All whole rock data were renormalised to be anhydrous and total iron is presented as $\mathrm{FeO}$
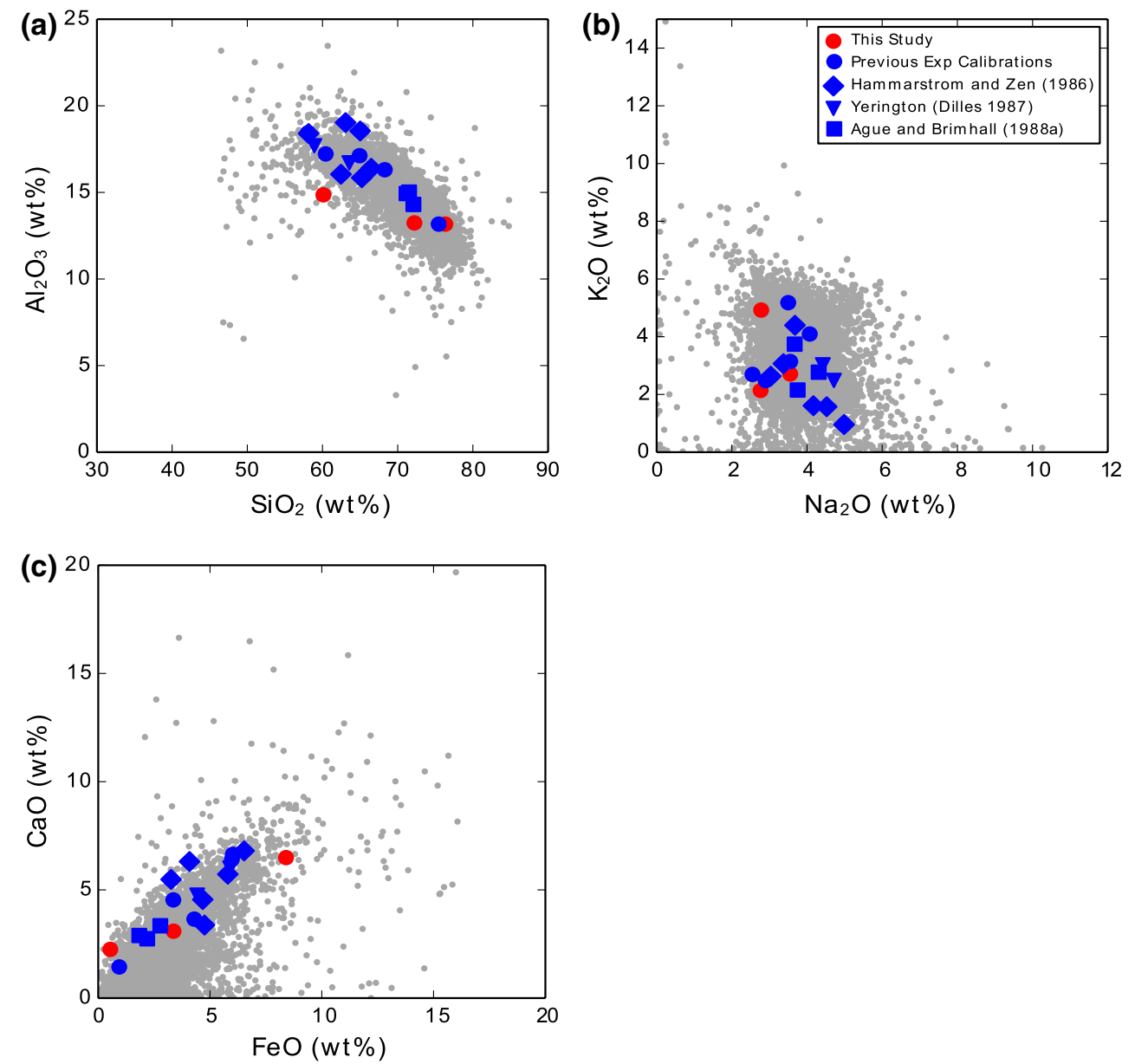

is relatively fresh. Pure water was added to powders in all experimental charges except that for CMA201, to which a $10 \mathrm{wt} \% \mathrm{NaCl}_{\mathrm{eq}}$ aqueous mixture was added. The total quantity of fluid added to each charge is given in Table 3 . All experiments were run in welded $\mathrm{Au}$ capsules. Weld integrity was assessed by heating overnight at $110{ }^{\circ} \mathrm{C}$ and checking afterwards for weight loss.

\section{Experimental methods}

Experimental details, including run conditions and starting materials, are provided in Table 3 and summarised below.

Low-pressure experiments (0.8-3 kbar) were performed using a combination of externally heated, rapid-quench water-pressurised Nimonic cold-seal vessels (hereafter "CSV") and gas-pressurised molybdenum-hafnium carbide or titanium-zirconium-molybdenum (collectively "TZM") vessels. A 3-mm OD, welded, Au capsule containing starting material plus water was loaded into the tip of a $\mathrm{Ni}$ alloy filler rod designed to sit in the hot-spot of the vessel. Oxygen fugacity was not externally buffered in the CSV apparatus, but has been shown to lie slightly above NNO through the agency of the Nimonic alloy, which is predominantly made of Ni. This redox state was confirmed by analyses of coexisting $\mathrm{Fe}-\mathrm{Ti}$ oxides in some runs (see below). In the TZM, $f \mathrm{O}_{2}$ was controlled by bleeding an $\mathrm{Ar}-\mathrm{H}_{2}$ mix into the Ar pressurising fluid. In both low-pressure apparatuses, heating was by external furnace; temperature was measured by a K-type thermocouple inserted into a well adjacent to the sample in the CSV or resting on the pressure vessel in the TZM, but calibrated for the offset with the sample temperature. The furnace was adjusted to maintain the required temperature at that thermocouple. Comparison with measurements made at the sample itself suggests the reading is within $\pm 5^{\circ} \mathrm{C}$. The systems were pressurised with a Haskel Air-Water pump, and pressure was measured using a digital pressure gauge calibrated against a Bourdon Gauge. For a typical run, it is usually possible to maintain the pressure during the run within \pm 20 bars of the desired value.

All low-pressure experiments were initially heated above the run temperature to fully or partially melt the starting material, before cooling to the run temperature. Starting materials for five MC1314 runs (R01, R02, R08, RB02, RB03) and CMA201 were held in the CSV for $24 \mathrm{~h}$ at $850{ }^{\circ} \mathrm{C}$, its upper operating temperature and then cooled manually to run temperature. The remaining low-pressure 


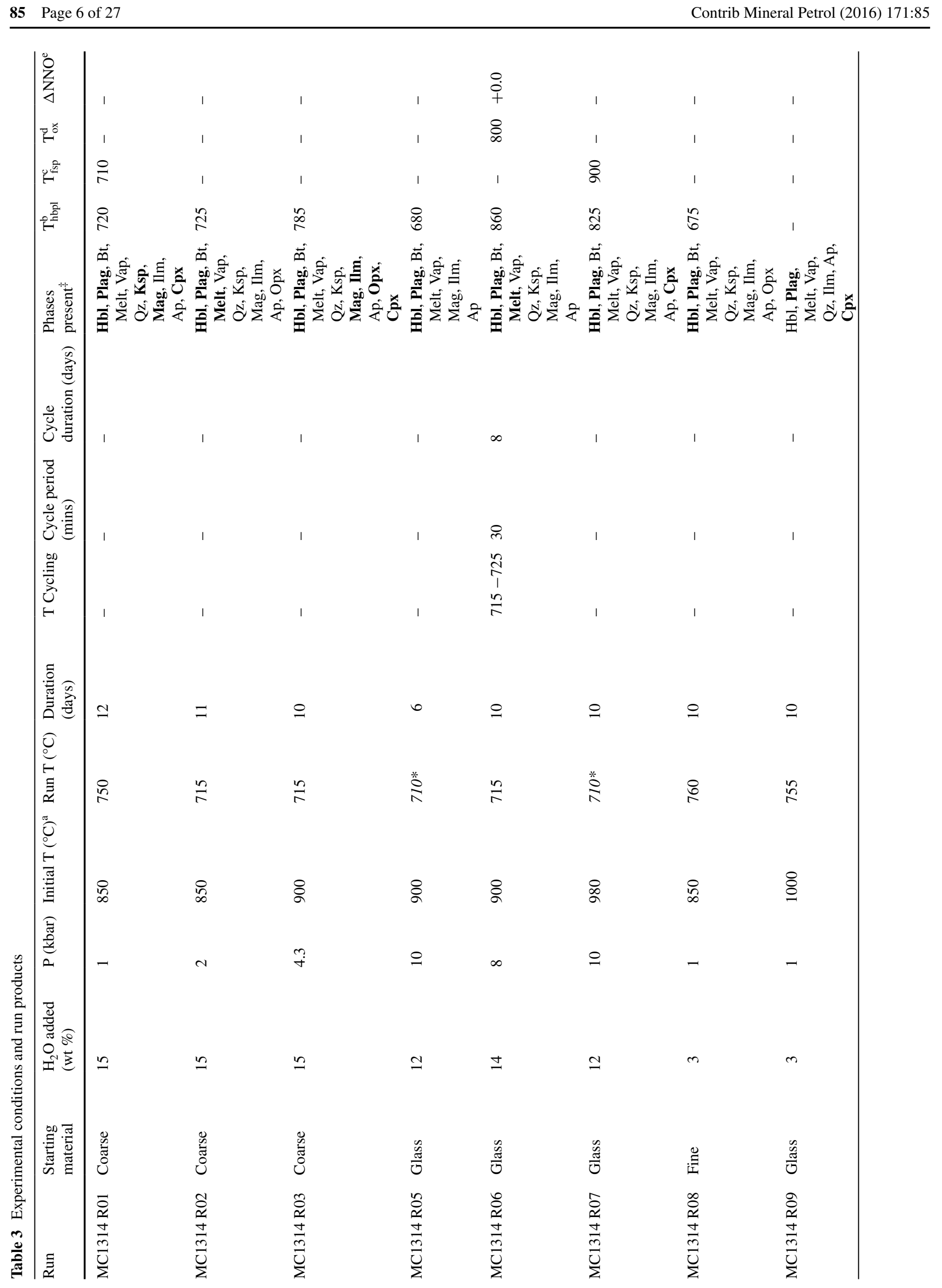

然 Springer 


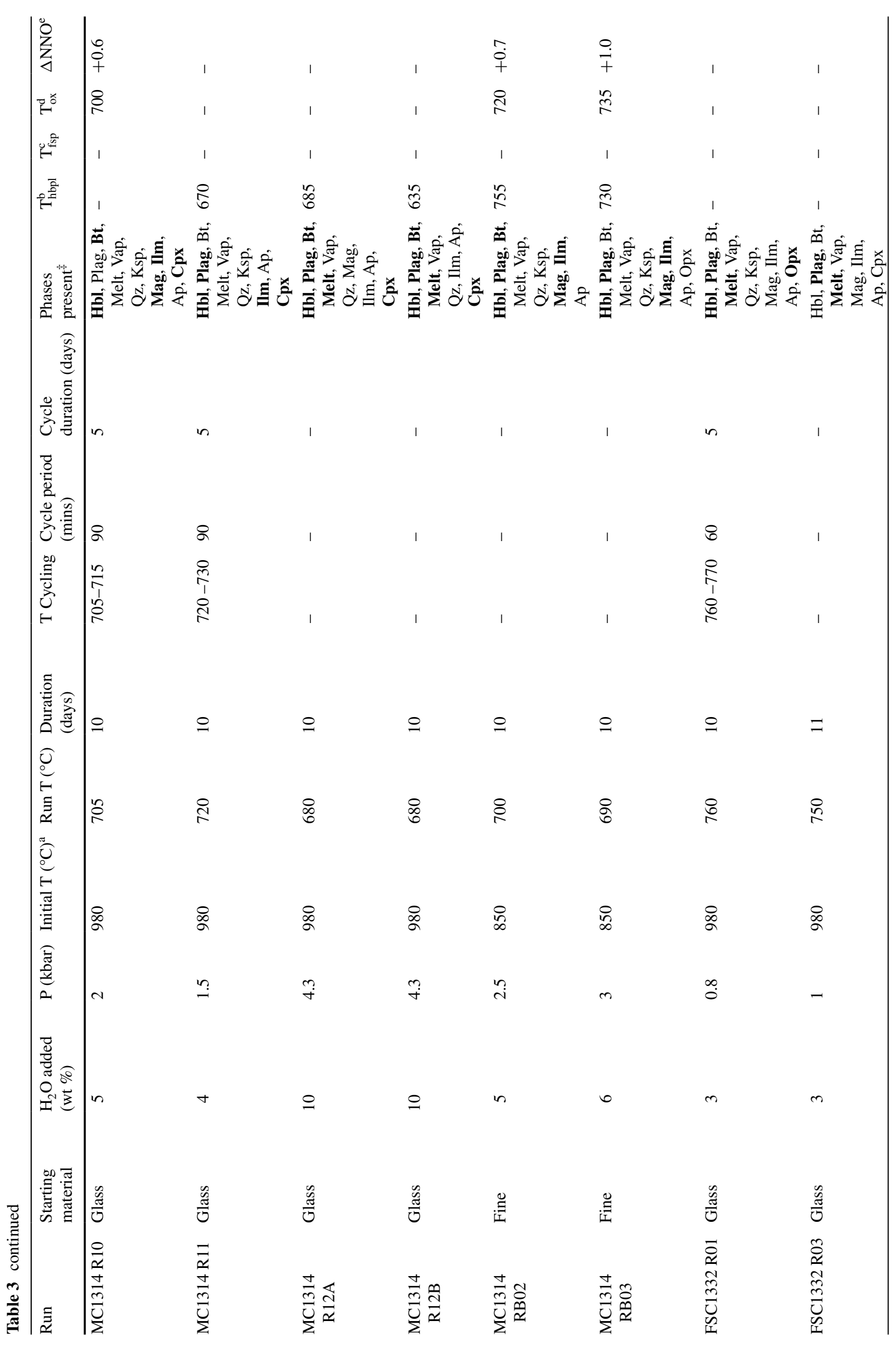




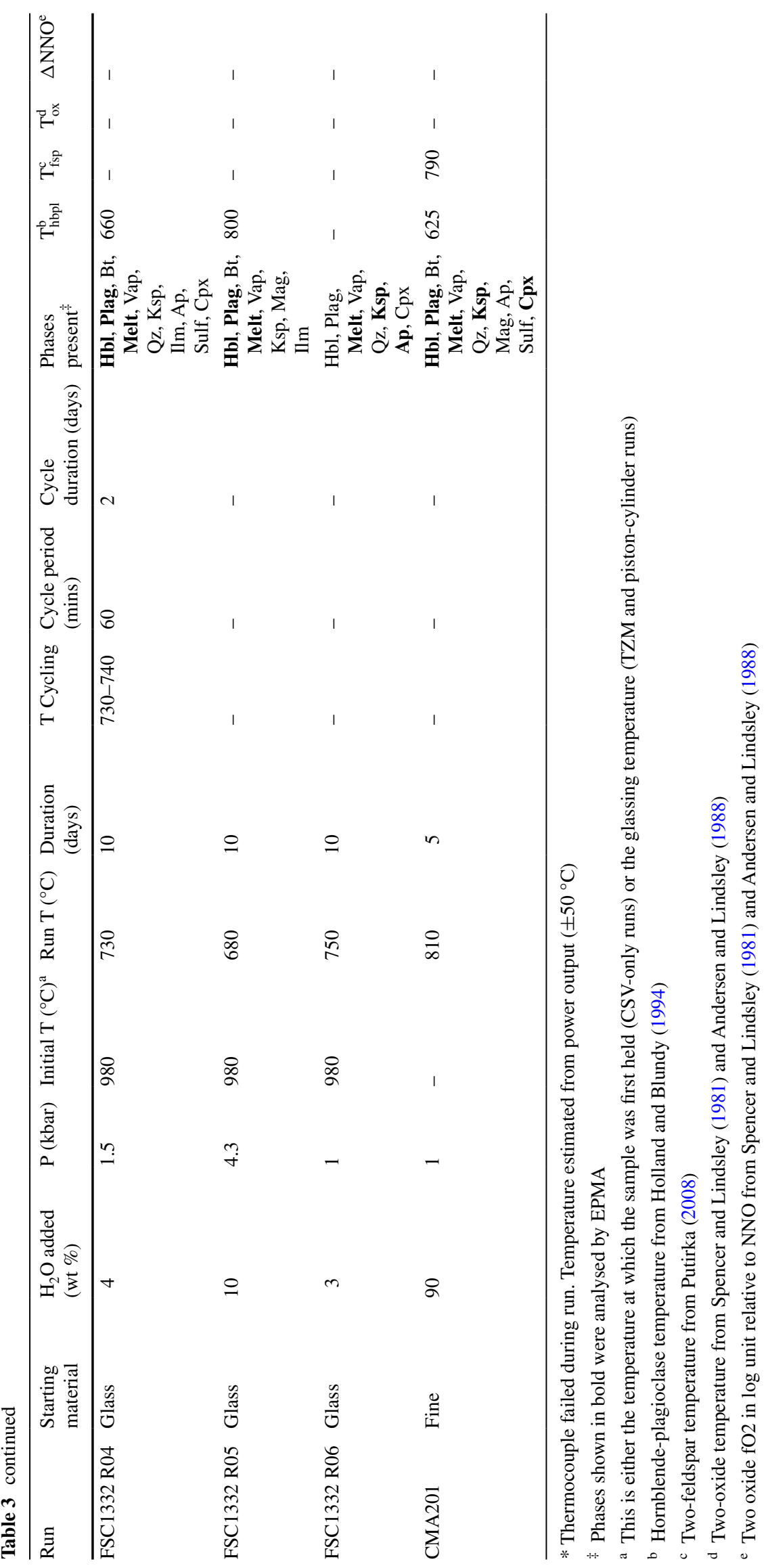


experiments were carried out in two stages: first, fully glassed, hydrous starting materials were made by heating Au capsules filled with fine-grained powder samples to $\sim 980{ }^{\circ} \mathrm{C}$ at 1.5 or $2 \mathrm{kbar}$ in the TZM for $3-4 \mathrm{~h}$ and rapidquenched; then, the same capsule was re-loaded into the CSV at $850{ }^{\circ} \mathrm{C}$ and promptly cooled at $10-20{ }^{\circ} \mathrm{C} / \mathrm{h}$ to run temperature. Run durations in the CSV $\left(705-810^{\circ} \mathrm{C}\right)$ ranged from 10 to 12 days, approximately twice as long as the experiments of Johnson and Rutherford (1989) at similar temperatures $\left(720-780{ }^{\circ} \mathrm{C}\right)$, and approximately half as long as the 2.5-6 kbar experiments of Schmidt (1992) at lower temperatures $\left(665-700{ }^{\circ} \mathrm{C}\right)$. In some experiments, in an effort to enhance the growth of larger amphibole crystals, the temperature was cycled, with an amplitude of $\pm 10{ }^{\circ} \mathrm{C}$, around the set-point with a period of $30-90 \mathrm{~min}$ for several days (Table 3) to promote Ostwald ripening (cf. Mills and Glazner 2013). At the end of the CSV runs, samples were isobarically rapid-quenched. The evolution of our experimental methodology highlights the difficulty of crystallising an intermediate to felsic equilibrium phase assemblage at low pressures to grain sizes adequate for microprobe analysis. On the other hand, the consistent results from experiments at similar conditions using different approaches (see below) serve as a useful test of reproducibility.

Moderate-pressure experiments (5-10 kbar) were carried out using a 3/4" inch talc-Pyrex assembly in an end-loaded piston-cylinder apparatus. Such a large assembly minimises frictional loss and shear stress at lower pressures (Johannes et al. 1971). A double capsule technique was used to buffer $\mathrm{fO}_{2}$. A $3 \mathrm{~mm}$ OD inner, crimped $\mathrm{Au}$ capsule containing equal parts Ni metal powder and distilled water, and packed with $\mathrm{Al}_{2} \mathrm{O}_{3}$ powder, was loaded into a $6 \mathrm{~mm}$ OD outer Au capsule containing the rock powder plus water. The outer capsule was welded shut with a lid in a 'trash can' like arrangement (Sneeringer and Watson 1985). Loaded, welded, double capsules were placed into a crushable alumina tube, surrounded with Pyrex powder, $\mathrm{MgO}$ powder and $\mathrm{MgO}$ discs, and inserted into a pressure cell comprising $\mathrm{Al}_{2} \mathrm{O}_{3}$ plugs, graphite furnace, Pyrex sleeve and talc sleeve, and wrapped in lead foil (McDade et al. 2002). The assembly was heated and pressurised in a similar fashion to Brooker et al. (1998) to minimise diffusive carbon infiltration, that can arise from a cracked furnace, into the sample capsule: cold-pressurisation to $\sim 3 \mathrm{kbar}$, held overnight, then heated to $\sim 600{ }^{\circ} \mathrm{C}$ (at this temperature the Pyrex softens), followed by gradual heating and pressurisation to $>900{ }^{\circ} \mathrm{C}$ and the target pressure (i.e. "hot piston-in" technique). Two pressure calibration schemes were used to account for frictional losses. At pressures of 8 and $10 \mathrm{kbar}$, we used a correction factor of $-3.6 \pm 1 \%$ (McDade et al. 2002); at lower pressures $(\leq 5 \mathrm{~kb})$, where frictional losses become much larger, we used a $-20 \pm 1 \%$ correction (Pistone et al. 2016). In all runs, temperature was maintained above $900{ }^{\circ} \mathrm{C}$ for approximately $24 \mathrm{~h}$, to ensure the starting material had melted, before being lowered to the target temperature at a rate of $\sim 10{ }^{\circ} \mathrm{C} / \mathrm{h}$. In one run (MC1314R06) temperature cycling similar to that described above was used. Temperature was measured using Type D axial thermocouples and controlled using a Eurotherm 902 digital controller. Experiments were quenched by turning off the power.

\section{Analytical methods}

Epoxy-mounted polished samples were prepared for sample characterisation and analysis.

Scanning electron microscopy (SEM) was carried out on a Hitachi S-3500 N instrument with $20 \mathrm{kV}$ accelerating voltage and $17 \mathrm{~mm}$ working distance. Phase identification was performed using energy dispersive (ED) spectra. Exhaustive searches were undertaken to establish the full phase assemblage, as some minerals were present in very low amounts.

Electron microprobe analysis (EPMA) was performed at the University of Bristol on either a JEOL JXA 8530F field-emission gun instrument or a Cameca SX100 instrument, both using five crystal wavelength dispersive spectrometers. For mineral analyses, the excitation volume was minimised by using a $10 \mathrm{kV}$ accelerating voltage; the beam current was $10 \mathrm{nA}$ focussed to a $1 \mu \mathrm{m}$ spot. Wherever possible, cores and rims of minerals were analysed to quantify any zoning, where present. For glass analyses (and some plagioclase crystals, where large enough), we used $15 \mathrm{kV}$ accelerating voltage with a defocussed $(15 \mu \mathrm{m}), 4 \mathrm{nA}$ beam to reduce alkali migration (cf. Humphreys et al. 2006). Calibration was carried out on a mixture of natural and synthetic minerals and oxides; glasses of known composition were used as secondary standards.

Ion microprobe analysis (SIMS) of gold-coated mounts was carried out at the University of Edinburgh NERC ionmicroprobe facility using a Cameca ims 1270 instrument with a primary beam of $\left(\mathrm{O}_{2}\right)^{-}$ions accelerated to $12.2 \mathrm{kV}$ and focussed to a $\sim 15 \mu \mathrm{m}$ diameter $4.2 \mathrm{nA}$ beam at the sample surface (net impact energy of $22.2 \mathrm{kV}$ ). Positive secondary ions, with a $75 \pm 20 \mathrm{~V}$ offset to reduce molecular ion transmission, were acquired over a total of 10 analytical cycles ( $\sim 10 \mathrm{~min}$ total analysis time). $\mathrm{CO}_{2}$ (as ${ }^{12} \mathrm{C}$ ) and $\mathrm{H}_{2} \mathrm{O}\left(\right.$ as $\left.{ }^{1} \mathrm{H}\right)$ were analysed at high mass resolution $(M / \Delta M \approx 3000)$ to resolve ${ }^{12} \mathrm{C}^{+}$from ${ }^{24} \mathrm{Mg}^{2+}$. The sample surface was sputtered for 2 min prior to analysis to remove surface contamination and a field aperture was used to limit the analytical volume to $15 \mu \mathrm{m}$ diameter. Calibration was carried out for ${ }^{30} \mathrm{Si}$-normalised ${ }^{1} \mathrm{H}$ and ${ }^{12} \mathrm{C}$ ratios against a range of rhyolitic glass standards with $\leq 1.04 \mathrm{wt} \% \mathrm{CO}_{2}$ and $\leq 10$ wt $\% \mathrm{H}_{2} \mathrm{O}$. Signals were background-corrected using session-averaged background count rates of $\sim 3 \mathrm{cps}$ for ${ }^{12} \mathrm{C}$ 
and $\sim 850 \mathrm{cps}$ for ${ }^{1} \mathrm{H}$ as determined on quartz grains in the run products and/or standard blocks. We additionally analysed for $\mathrm{MgO}\left(\right.$ as ${ }^{26} \mathrm{Mg}^{+}$) and for $\mathrm{CaO}\left(\right.$ as $\left.{ }^{44} \mathrm{Ca}^{2+}\right)$ using glass standards for calibration. These data provide more accurate values for glass $\mathrm{MgO}$ than EMPA at very low concentrations $(<0.1 \mathrm{wt} \%)$; for $\mathrm{CaO}$ the SIMS data provide a cross-check against EMPA. Analyses showing obvious crystal overlap, evident from elevated $\mathrm{MgO}$ or $\mathrm{CaO}$, were discarded, as were those with continuously falling ${ }^{1} \mathrm{H}$ or

${ }^{12} \mathrm{C}$ signals during analysis.

\section{Experimental results}

Experimental phase assemblages are given in Table 3, EMPA analyses of quenched glasses in Table 4 and minerals in Tables 5, 6, 7, 8, 9, 10. Back-scattered electron photomicrographs of representative run products are presented in Fig. 2.

All but three of the twenty runs reported in Table 3 contained amphibole, biotite, plagioclase, quartz, $\mathrm{Fe}-\mathrm{Ti}$ oxides, apatite, vesicles (vapour) and quenched melt (glass). Alkali feldspar, which is rare, typically fine-grained and very difficult to identify in BSE images, was positively identified in 15 runs. Pyroxenes (both ortho and clino) occur in approximately half of the runs, usually in association with (e.g. as inclusions in) amphiboles. Sulphides were observed in FSC1332R04 and CMA201 only.

The textures of run products varied according to the nature of the starting material and the experimental method used. In CSV experiments with coarse-grained starting material (Fig. 2a), pools of glass form between large $(<100 \mu \mathrm{m})$ resorbed, relict grains of plagioclase, quartz and biotite. Relict alkali feldspar grains develop a patchy texture suggestive of partial melting and exsolution during the run. Between the relict grains, small $(10-50 \mu \mathrm{m})$ euhedral grains of amphibole, plagioclase and oxides form, along with clusters of tiny $(\sim 1 \mu \mathrm{m})$ alkali feldspars. Amphiboles often show thin, outer rims $<10 \mu \mathrm{m}$ wide of slightly more Mg-rich composition. Vesicles appear to form an interconnected network. Glass is free of microvesicles. In CSV experiments using glassed starting materials, relict crystals are conspicuously absent (Fig. 2b). Vesicles are isolated and typically $>20 \mu \mathrm{m}$ in diameter. Matrix glass is again microvesicle-free. Plagioclase is abundant and typically lath-like with evidence for very thin $(\leq 2 \mu \mathrm{m})$ more calcic rims, possibly grown during quench. Subhedral amphiboles tend to form in clusters, often associated with pyroxenes. In the $0.8 \mathrm{kbar}$ run FSC1332R01 (Fig. 2b), the intergrowths of amphibole and orthopyroxene suggest that this experiment lies close to the low-pressure limit of amphibole stability. Similar features involving amphibole and clinopyroxene were observed in FSC1332R04.
High-pressure runs (Fig. 2c-f) are consistently free of relict grains. At $10 \mathrm{kbar}$ (Fig. 2c) and 8 kbar (Fig. 2d), run product crystals are uniformly fine-grained and euhedral, surrounded by small pools of glass, and uniformly distributed throughout the capsule. Amphiboles often display relatively $\mathrm{Fe}$-rich cores and/or clinopyroxene cores that are thought to represent nuclei formed either during glassing, or during subsequent cooling to run temperature (Fig. 2e). Smaller crystals lack such cores and were selected for EMPA analysis. All crystals contain very thin $(<5 \mu \mathrm{m})$ outermost rims of more Fe-rich composition, which we ascribe to growth during quench. Plagioclase crystals may show zoning from more calcic cores (Fig. 2d), thought to be high-temperature relicts, to less calcic outer rims that we selected for EMPA analysis. Biotites are uniformly acicular and too fine-grained for EMPA analysis (Fig. 2f) in almost all runs except for rare, ragged, poorly polished larger grains (Fig. 2c). There are two size populations of vesicles within the quenched glasses. The larger population ( $\geq 20 \mu \mathrm{m}$ diameter) is distributed randomly through the capsules (e.g. Figure 2e, f) and is thought to represent volatile saturation at run conditions. The second population of tiny vesicles $(<1 \mu \mathrm{m}$ diameter $)$ is interpreted to form upon quenching, suggestive of prograde solubility (i.e. decreasing with decreasing temperature). Microvesicles are particularly abundant at $4.3 \mathrm{kbar}$ and $680^{\circ} \mathrm{C}$ (Fig. 2e, f). Similar microvesicles are present, but much harder to discern at 8 (Fig. 2d) and 10 kbar, because the glass pools are generally much smaller. It would appear that water solubility remains prograde at pressures above $4.3 \mathrm{kbar}$. The lack of microvesicles below $4.3 \mathrm{kbar}$ (Fig. 2a, b) and their presence at and above this pressure suggest the transition from retrograde to prograde solubility occurs between 3 and $4.3 \mathrm{kbar}$. This is consistent with Paillat et al's (1992) experiments on albite glass, where they document a solubility change from retrograde to neutral (temperature-insensitive) to prograde in the 4-5 kbar pressure interval.

\section{Phase chemistry}

\section{Glasses}

EMPA analyses of quenched glasses from 13 runs are given in Table 4. A subset of runs, where glass pools were large enough, were analysed for $\mathrm{H}_{2} \mathrm{O}$ and $\mathrm{CO}_{2}$ by SIMS. The glasses are uniformly high-silica rhyolites, with $\mathrm{SiO}_{2}$ contents that increase with decreasing pressure (Fig. 3a), consistent with the increase in silica solubility at the ternary minimum in the haplogranite system as pressure decreases (Tuttle and Bowen 1958; Johannes and Holtz 1996). This trend is more pronounced in our data if we exclude run CMA201 that was equilibrated at temperatures well above 


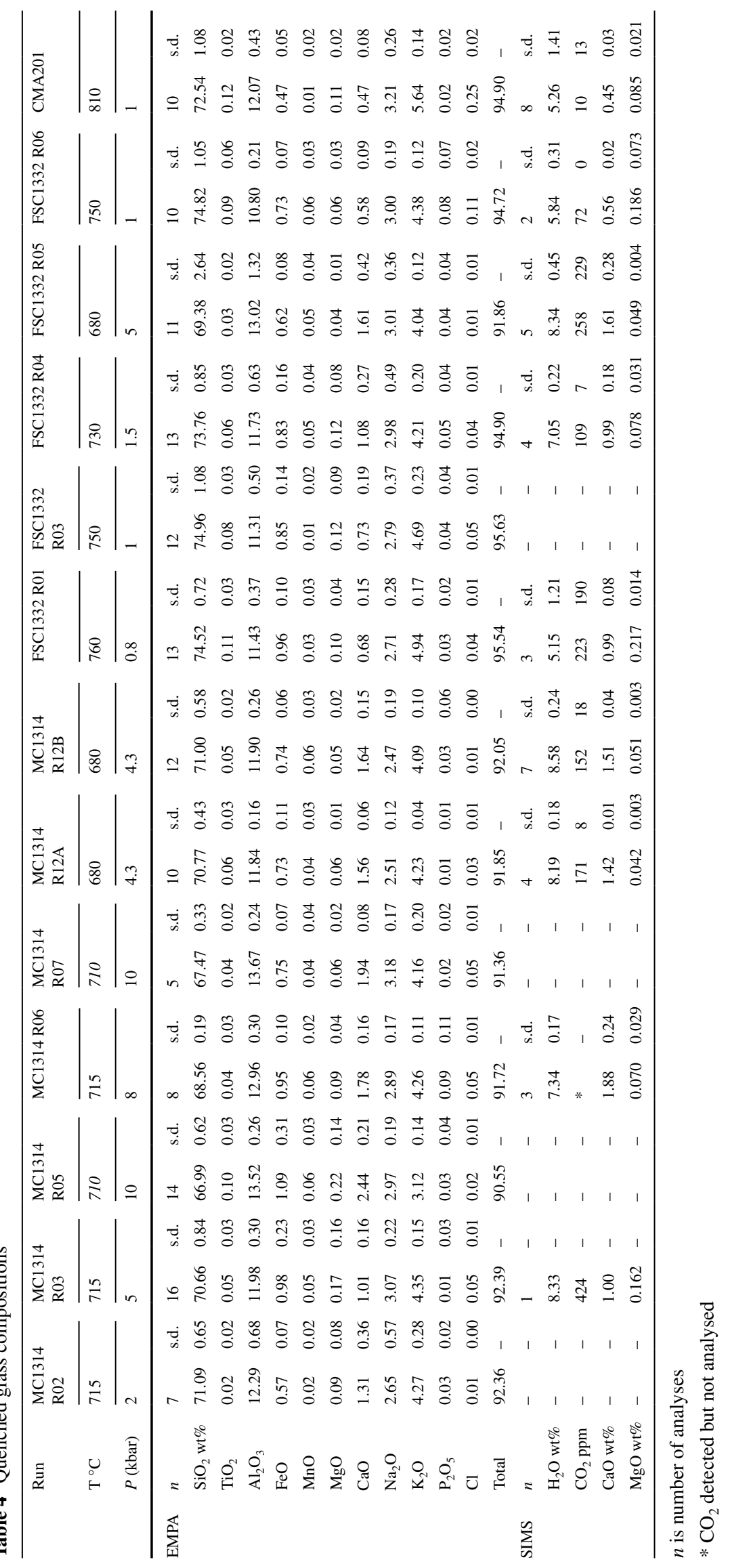




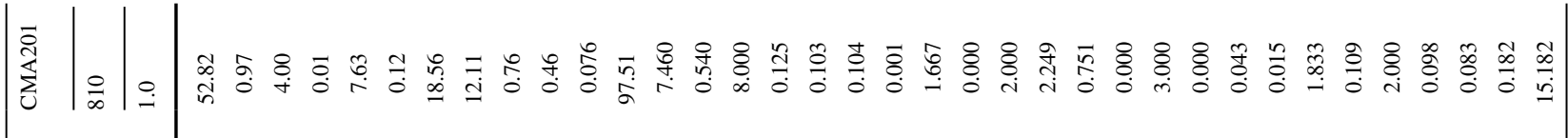

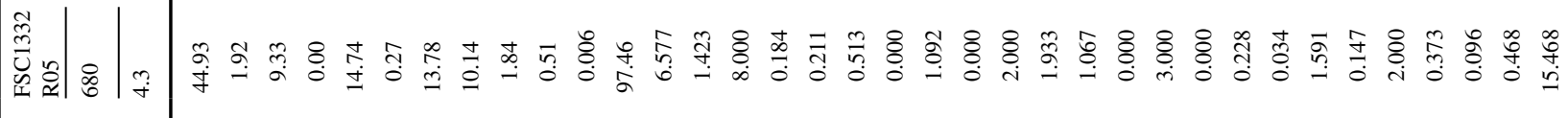

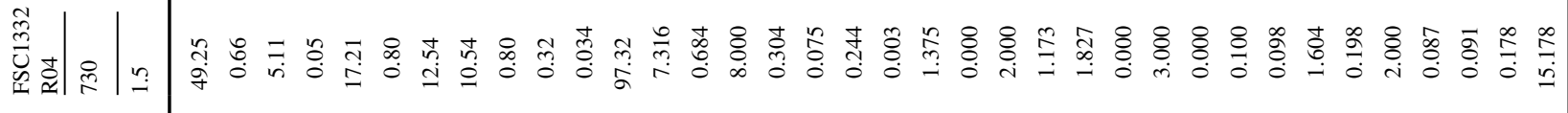

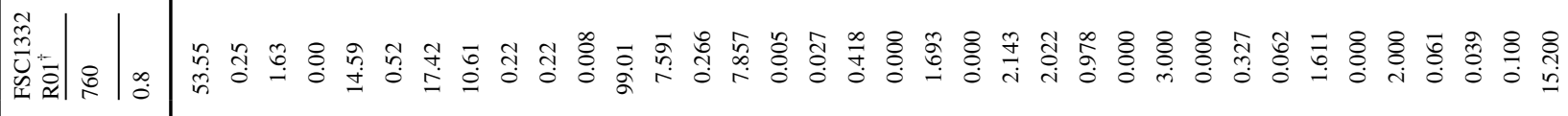

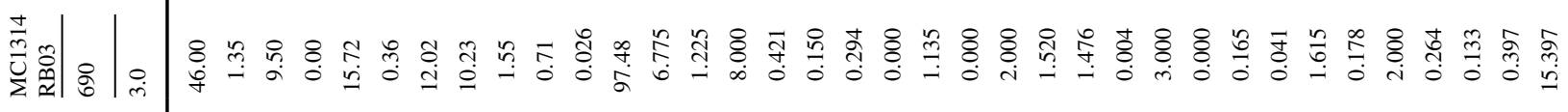

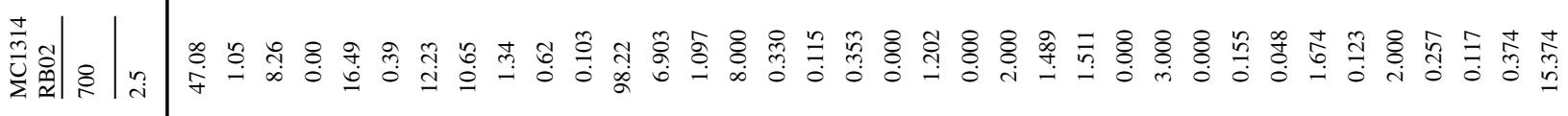

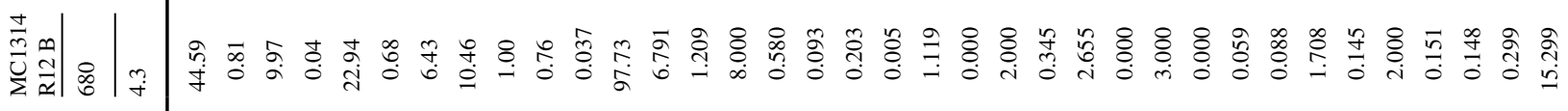

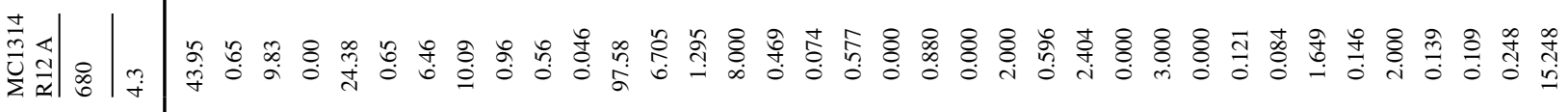

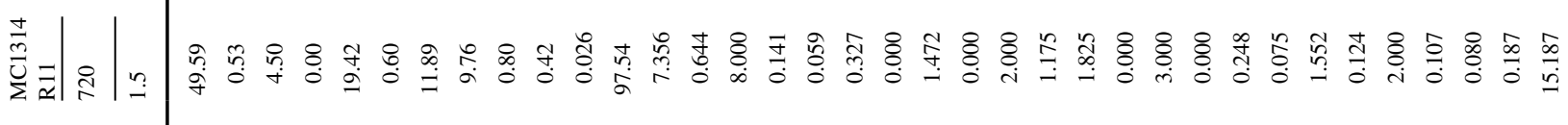

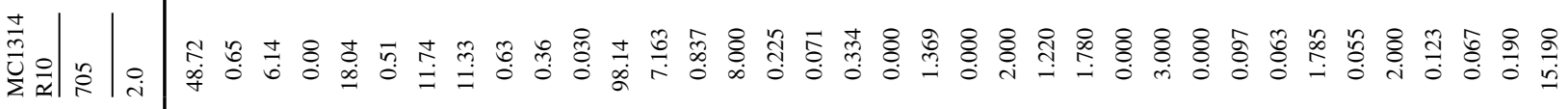
苟|

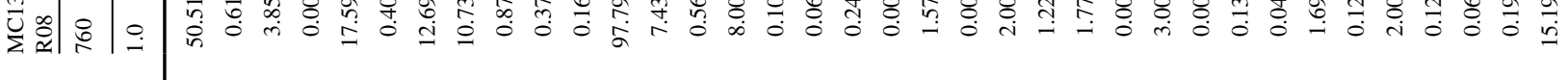

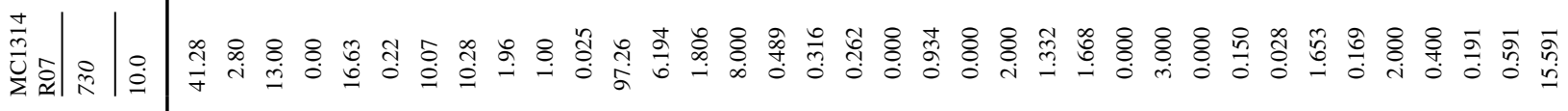

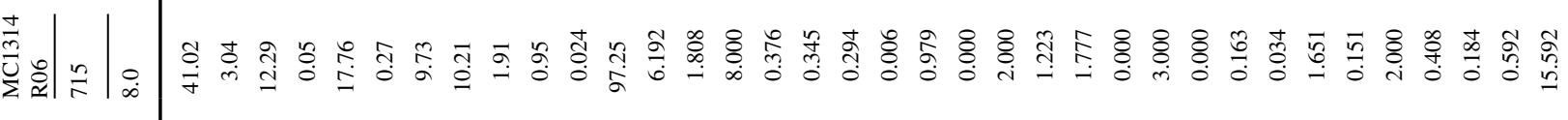

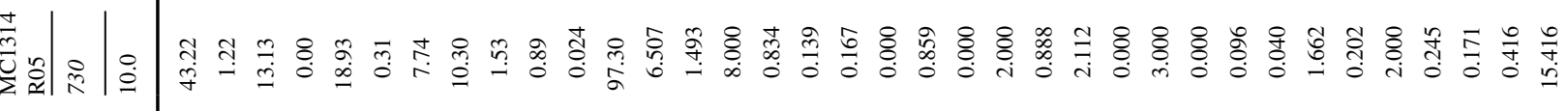

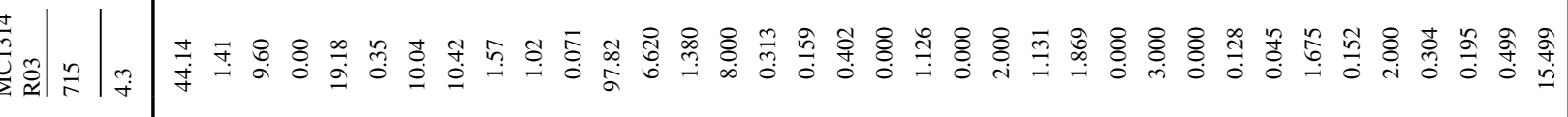

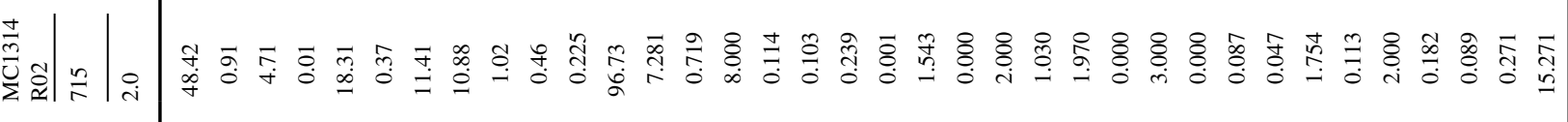

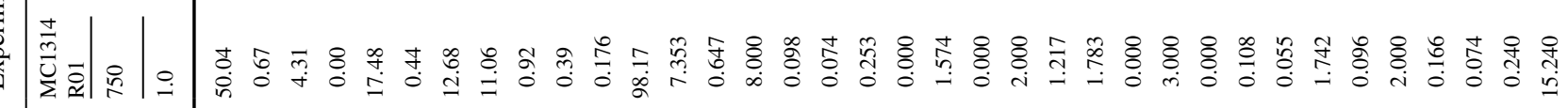

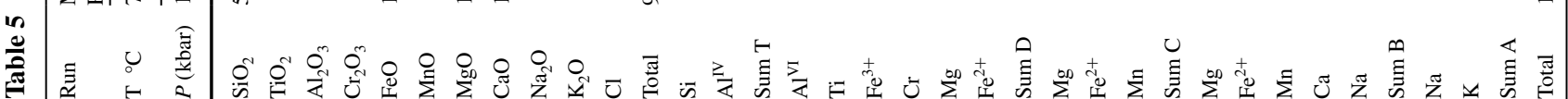




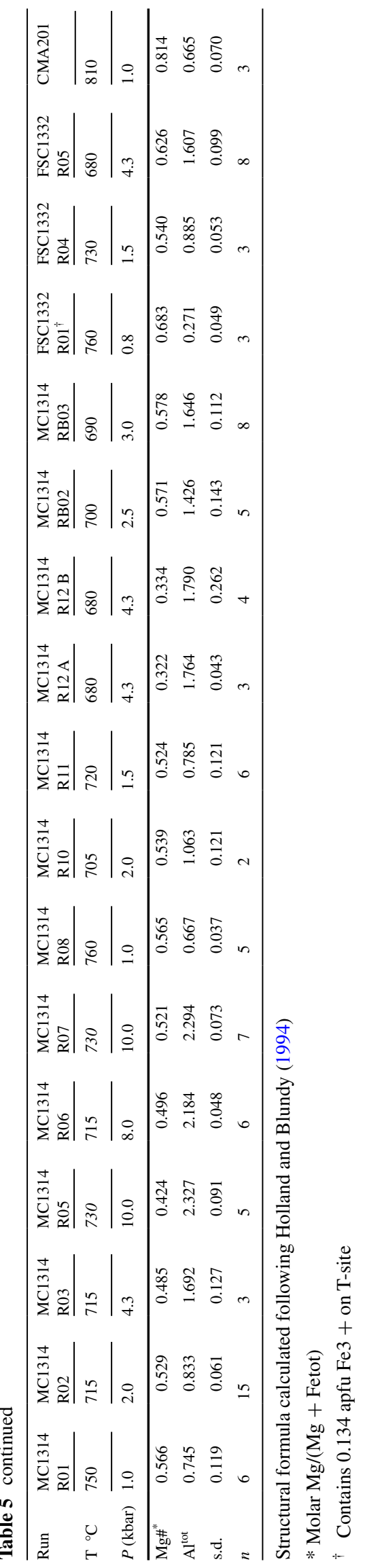

the ternary minimum. $\mathrm{Al}_{2} \mathrm{O}_{3}$ (not shown) and $\mathrm{CaO}$ (Fig. 3b) contents decrease with decreasing pressure, largely due to plagioclase crystallisation. In Fig. 4, we project the glasses into the haplogranite $\mathrm{Qz}-\mathrm{Ab}-\mathrm{Or}$ ternary using calculated CIPW norms (with $\mathrm{Fe}^{3+} / \Sigma \mathrm{Fe}=0.2$ ) and the correction scheme for normative anorthite (An) content of Blundy and Cashman (2001). The experimental glasses show clearly a migration towards the Qz apex and away from the $\mathrm{Ab}$ apex with decreasing pressure. At lower pressures, there is excellent agreement between our projected glasses and the locations of the ternary minima of Johannes and Holtz (1996). At pressures above $4 \mathrm{kbar}$, our glasses are displaced to higher Qz contents.

Dissolved $\mathrm{H}_{2} \mathrm{O}$ contents range from 5.2 to $8.6 \mathrm{wt} \%$ (Table 4). Dissolved $\mathrm{CO}_{2}$ contents are consistently low $(<500 \mathrm{ppm})$, except in the single analysed piston cylinder run at $8 \mathrm{kbar}$ (MC1314 R06), where significant $\mathrm{CO}_{2}$ was detected by SIMS, although not quantified. This high $\mathrm{CO}_{2}$ almost certainly derives from the graphite furnace, which is inevitable in long-run duration, high-pressure piston cylinder runs (Brooker et al. 1998) even with gold capsules. It is striking, however, that no such elevated $\mathrm{CO}_{2}$ is evident in 4.3 kbar runs. Glass volatile contents can, in principle, be used to recover experimental pressures and/or derive solubility models for liquids close to the granite ternary minimum. However, as noted above, glasses appear to show both prograde and retrograde solubilities. Retrograde solubility means that during quench the dissolved water content of glasses can increase above the saturation value at run conditions, whereas prograde solubility will lead to water exsolution. Only when solubility is neutral (in this case at or around $5 \mathrm{kbar}$ ), or when quench rates are extremely rapid will the volatile content of quenched glasses match that at run conditions. For each of our glasses with SIMS data, we have determined the apparent pressure of saturation using the solubility model MAGMASAT of Ghiorso and Gualda (2015). At 4.3 kbar run pressure, the calculated pressure for four runs (MC1314 R03, $\mathrm{R} 12 \mathrm{~A}, \mathrm{R} 12 \mathrm{~B}$ and FSC1332 R05) is $4.33 \pm 0.16$ kbar. The agreement suggests that the total mass of water exsolved into tiny microvesicles (e.g. Figure $2 \mathrm{f}$ ) is very small. In contrast, calculated saturation pressures at run temperature for low-pressure, CSV runs consistently overestimate run pressure by $0.5-1.2 \mathrm{kbar}$. As the CSV apparatus has no pressure calibration issues, the overestimation of pressure means that either the solubility models are incorrect or that the dissolved volatile content is modified on quench. It is not possible at present to distinguish between these possibilities, although it is worth noting that all of the solubility data at pressures below 2 kbar and temperatures below $750{ }^{\circ} \mathrm{C}$ used in the MAGMASAT calibration come from experimental studies carried out long before the advent of SIMS characterisation of run products. Conversely, 

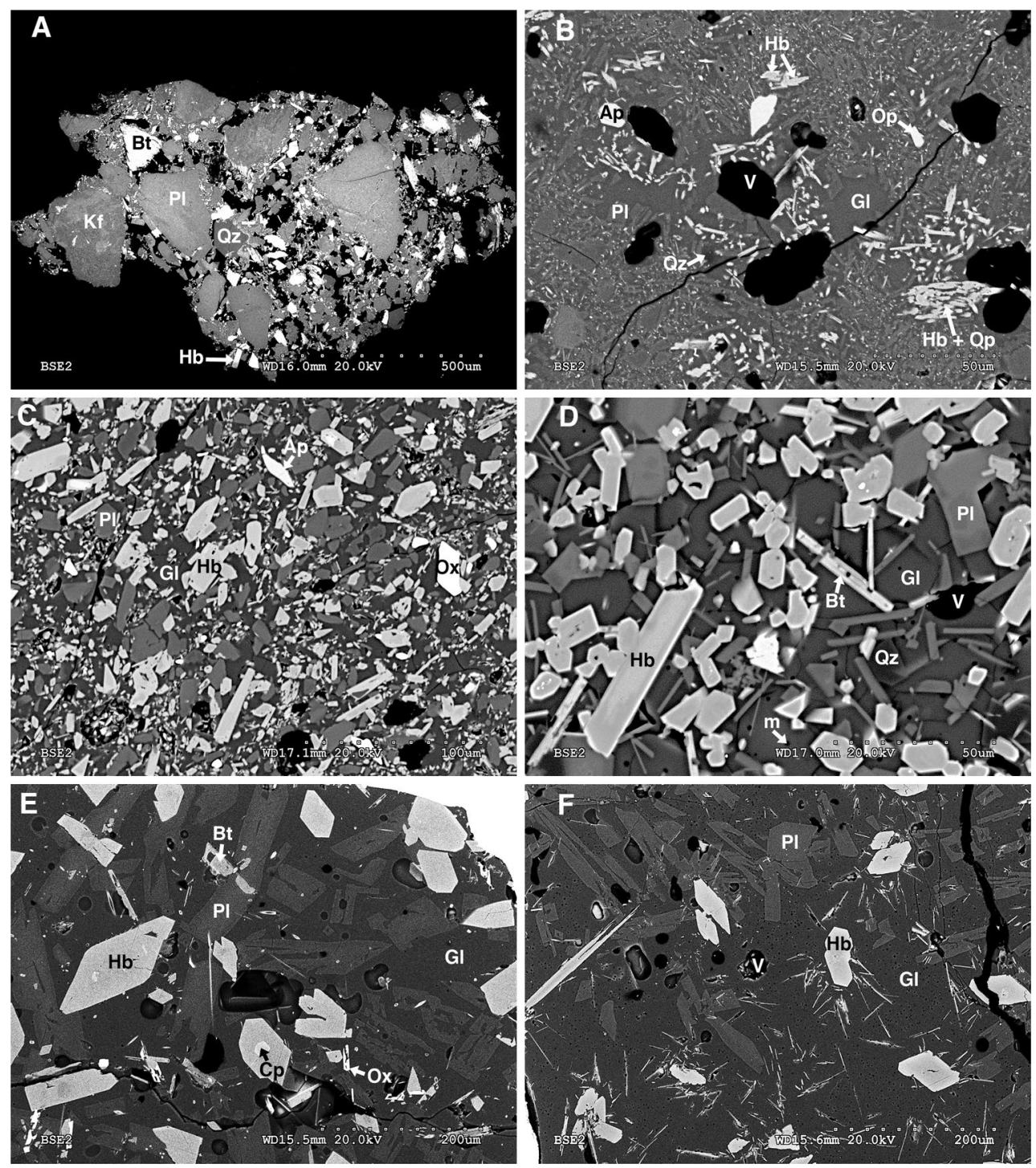

Fig. 2 Representative back-scattered electron (BSE) images of experimental run products. a CSV run MC1314R02 at 2 kbar with coarse-grained starting materials. Large relict grains of quartz $(\mathrm{Qz})$, plagioclase $(\mathrm{Pl})$, biotite $(\mathrm{Bt})$ and mottled alkali feldspar $(\mathrm{Kf})$ sit in finer grained matrix of glass with newly grown crystals, including euhedral hornblende $(\mathrm{Hb})$ and plagioclase and aggregates of alkali feldspar. b CSV run FSC1332R01 at 0.8 kbar using glassed starting material. Large pools of glass $(\mathrm{Gl})$ contain small euhedral hornblende, orthopyroxene (Op), often forming clusters, plagioclase, quartz and apatite (Ap). Biotite forms very fine-grained needles. Note large vesicles (V). c Piston cylinder run MC1314R05 at $10 \mathrm{kbar}$. Equigranular texture of zoned hornblende, oxides (Ox), apatite, plagi-

McIntosh et al. (2014) provide evidence for $\mathrm{H}_{2} \mathrm{O}$ resorption during cooling of experimental glasses, suggestive of retrograde solubility.

According to the solubility model of Ghiorso and Gulada (2015), regardless of the exact saturation pressures calculated, the observed ratio of dissolved $\mathrm{H}_{2} \mathrm{O}$ to $\mathrm{CO}_{2}$ in the glasses is consistent with $\mathrm{XH}_{2} \mathrm{O}$ in the coexisting fluid oclase and glass. Biotite forms tiny needles within the glass and rarer ragged laths. Only hornblende rim analyses were used for barometry. d 8 kbar run MC1314R06 showing euhedral, zoned hornblendes, thin biotite laths, zoned plagioclase, alkali feldspar clusters and quartz $(\mathrm{Qz})$ in glass with rare microvesicles ( $\mathrm{m}$-arrowed). Some hornblendes have oxide inclusions. e $4.3 \mathrm{kbar}$ run MC1314R12A showing euhedral hornblende and plagioclase in glass matrix. Biotite forms tiny needles; oxides tend to have hollow cores. Some hornblendes have clinopyroxene (Cp) cores. Note two sizes of vesicles; large ones due to vapour saturation at run conditions; tiny ones (arrowed) due to exsolution upon quench. f $4.3 \mathrm{kbar}$ run FSC1332R05. Abundant acicular biotites and microvesicular glass are readily apparent

of $>0.9$ in all runs except that at $0.8 \mathrm{kbar}(\sim 0.8) .{ }^{1}$ This is consistent with the apparent location of the low-pressure glass compositions close to the water-saturated ternary minima in Fig. 4. In the 8 and 10 kbar runs, $X_{2} \mathrm{O}$ may be

\footnotetext{
1 The presence of small amounts of $\mathrm{CO}_{2}$ in the low pressure glasses is probably inherited from the natural starting materials.
} 
Fig. 3 EMPA analyses of quenched glasses as a function of pressure. $\mathbf{a} \mathrm{SiO}_{2} ; \mathbf{b ~ C a O}$. Analyses are normalised to $100 \%$ anhydrous; error bars are 1 s.d. Data are taken from Table 4. Higher temperature run CMA201 is indicated
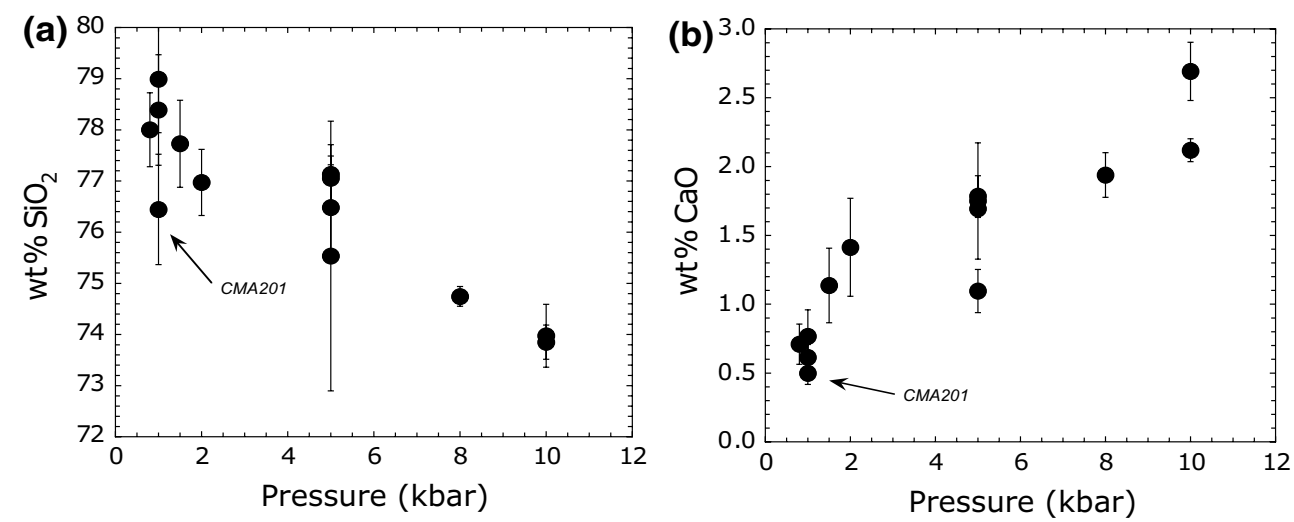

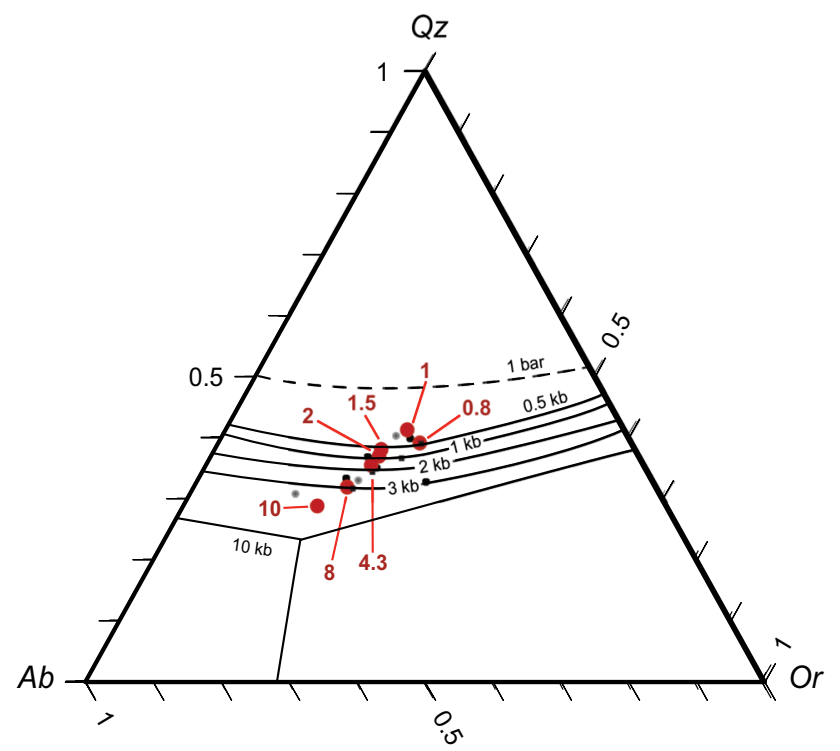

Fig. 4 Haplogranite ternary: quartz (Qz)—albite (Ab)—orthoclase (Or) in weight fraction units. The positions of the water-saturated quartz + feldspar cotectics are shown as lines, labelled with pressure (from Johannes and Holtz 1996). The small square on the lower pressure lines denotes the ternary minima; the system is eutectic at 10 kbar. Red circles (labelled with the experimental pressure) are the CIPW norms of the experimental glasses from this study projected into the ternary using the method of Blundy and Cashman (2001) to account for anorthite component

significantly lower due to the presence of significant, but unquantified $\mathrm{CO}_{2}$; this may contribute the deviation of the higher pressure glasses from the corresponding water-saturated haplogranite cotectics.

\section{Amphiboles}

Amphibole analyses are reported for 17 of the experiments reported in Table 5. For each run, we provide 3-10 analyses of amphibole rims after screening a larger set of analyses for obvious signs of contamination by adjacent phases, analytical total ( $>97 \mathrm{wt} \%$ ) and for stoichiometry.
Contamination was a particular problem because of the small grain size of the amphiboles. We eliminated analyses of relict amphiboles, i.e. those whose chemistry was a close match to the starting material amphiboles reported in Table 2. In general, such amphiboles are characterised by higher $\mathrm{Cl}$ contents than those grown in the experiments. Finally, in a few runs, we also eliminated crystal cores (e.g. Figure 2c) that appear to have nucleated during cooling of the glassed starting materials to the run temperature in the CSV apparatus. Such analyses were readily distinguished by lower $\mathrm{Mg \#}$ and higher Ti contents than the equilibrium amphiboles. In runs at low pressure, amphiboles sufficiently large to analyse were rather scarce presumably because the experimental conditions lie close to the minimum pressure of amphibole stability. This problem was most acute at $0.8 \mathrm{kbar}$ (FSC1332R01) because amphibole is often involved in very fine-grained intergrowth with orthopyroxenes (Fig. 2b) and contamination was endemic. Also, as noted by Schmidt (1993), identifying new overgrowth rims is hardest when the new amphibole and the amphibole in the starting materials are close in composition, notably $\mathrm{Al}$ content. For our MC1314 experiments this problem was most acute in the 2 kbar runs (MC1314R10 and R02). Amphibole structural formulae were calculated using a modification to the method of Holland and Blundy (1994), which makes an approximation of octahedral site $\mathrm{Fe}^{3+}$ using stoichiometric constraints on the minimum and maximum permissible $\mathrm{Fe}^{3+}$. In the modified version, we give $2 / 3$ weight to the lower constraint on $\mathrm{Fe}^{3+}$ and $1 / 3$ weight to the upper constraint. (This procedure cannot be used for amphiboles with tetrahedral $\mathrm{Fe}^{3+}$ ).

All of the experimental amphiboles classify as calcic ( $>1.5 \mathrm{Ca}$ apfu) and lie within the compositional range defined by hornblende (Leake et al. 2003). Mg-numbers $\left(\mathrm{Mg} \#=\right.$ molar $\left.\mathrm{Mg} /\left[\mathrm{Mg}+\mathrm{Fe}^{\mathrm{tot}}\right]\right)$ range from 0.32 to 0.81 . With increasing pressure, there is an observed transition from tremolite-rich amphiboles to pargasitic and tschermakitic amphiboles that contain more tetrahedral $\mathrm{Al}\left(\mathrm{Al}^{\mathrm{iv}}\right)$. 

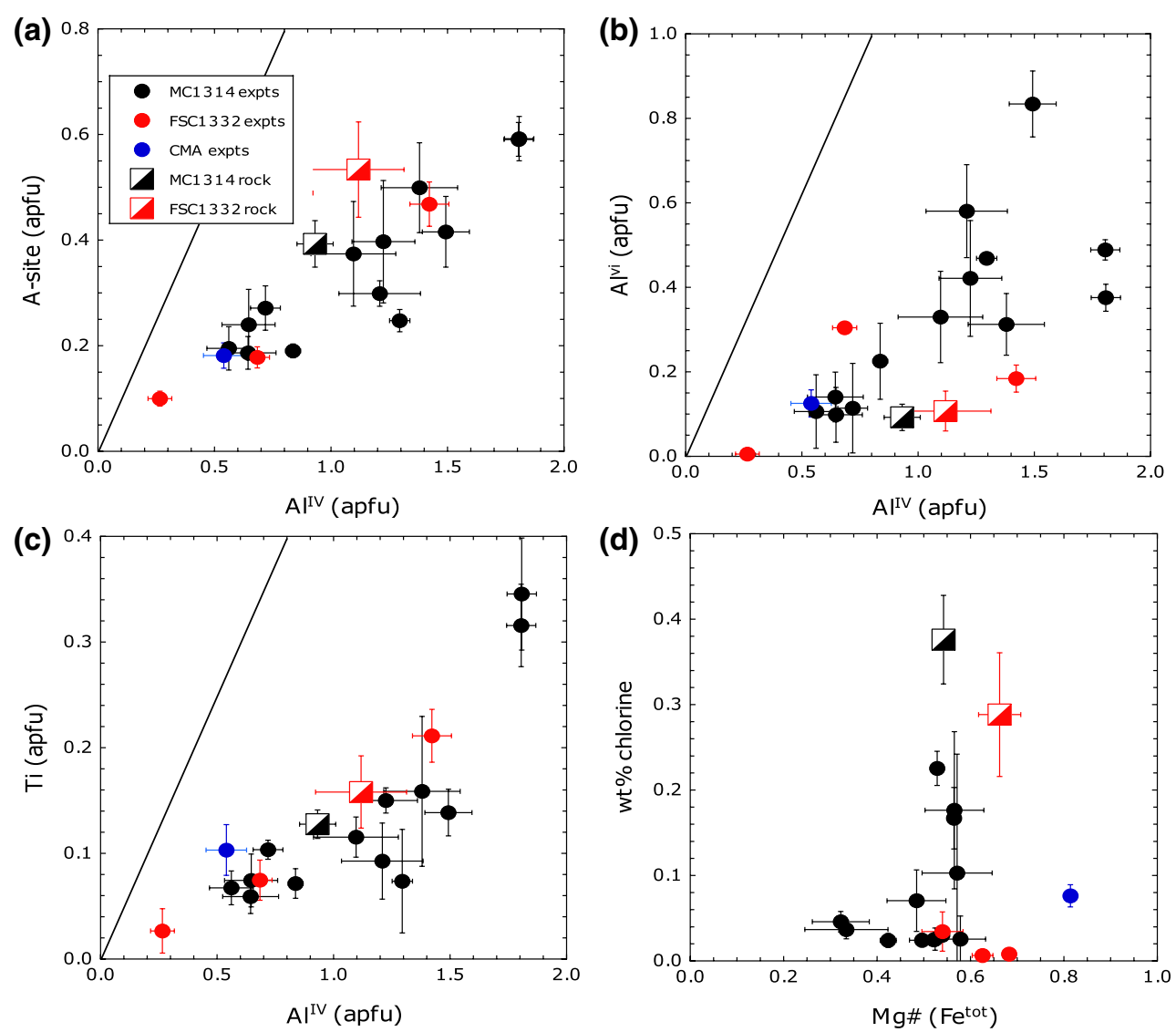

Fig. 5 Compositional variation in experimental amphiboles (Table 5) and the natural starting materials (Table 2). a A-site occupancy $\left(\mathrm{Na} \mathrm{A}_{\mathrm{A}}+\mathrm{K}_{\mathrm{A}}\right)$ versus tetrahedral aluminium $\left(\mathrm{Al}^{\mathrm{iv}}\right)$; b octahedral aluminium $\left(\mathrm{Al}^{\mathrm{vi}}\right)$ versus $\left(\mathrm{Al}^{\mathrm{iv}}\right)$; c titanium versus $\left(\mathrm{Al}^{\mathrm{iv}}\right)$; (d) chlorine (wt\%) versus $\mathrm{Mg \# .} \mathrm{The}$ solid lines in each plot show the end-member, stoichiometric exchange vectors given in the text. Error bars are 1 s.d. of the amphibole mean structural formula

The dominant exchange vectors are: $\left[\mathrm{Mg}, \mathrm{Fe}^{2+}\right] \mathrm{Si}=$ $\mathrm{Al}^{\mathrm{vi}} \mathrm{Al}^{\mathrm{iv}},\left[\mathrm{Mg}, \mathrm{Fe}^{2+}\right] \mathrm{Si}_{2}=\mathrm{Ti}\left[\mathrm{Al}^{\mathrm{iv}}\right]_{2}$ and $\square \mathrm{Si}=[\mathrm{Na}, \mathrm{K}]_{\mathrm{A}} \mathrm{Al}^{\mathrm{iv}}$, as revealed in plots, against $\mathrm{Al}^{\text {iv }}$, of A-site occupancy (Fig. 5a), Al ${ }^{\text {vi }}$ (Fig. 5b) and Ti (Fig. 5c). Amphiboles from 0.8 kbar run FSC1332R01 are unusual in that they contain no octahedral $\mathrm{Al}$ and instead appear to have appreciable tetrahedral $\mathrm{Fe}^{3+}$ (Table 5), features previously observed for low-pressure ( $0.5 \mathrm{kbar})$ calcic amphiboles from granites on the Isle of Skye (Ferry 1985). Although there is some overlap between starting material amphiboles and experimental amphiboles for some experiments in terms of the parameters plotted in Fig. 5a-c, the difference between starting materials and experimental amphiboles is always evident in chlorine content, which is consistently higher in the natural amphiboles (Fig. 5d).

In terms of correlation with intensive variables, the most striking correlation is between $\mathrm{Al}^{\text {tot }}$ and pressure (Fig. 6a). However, in contrast to previous barometer calibrations, this correlation is demonstrably nonlinear showing a steepening slope below $3 \mathrm{kbar}$ and a positive pressure intersection at $\mathrm{Al}^{\text {tot }}=0$. There are also similar curved (or kinked) correlations between $\mathrm{Al}^{\mathrm{iv}}$ and pressure (Fig. 6b) and $\mathrm{Al}^{\mathrm{vi}}$ or $\mathrm{Ti}$ and pressure (not shown), but these show smaller ranges and greater scatter. The implication is that pressure operates on a number of exchange vectors that involve both $\mathrm{Al}^{\mathrm{iv}}$ and $\mathrm{Al}^{\mathrm{vi}}$, such that the $\mathrm{Al}^{\text {tot }}$ versus $\mathrm{P}$ correlation is the most robust. Moreover, there is no difference for the pressure dependence on $\mathrm{Al}^{\text {tot }}$ in the three different starting materials, suggesting that this relationship between $\mathrm{Al}^{\text {tot }}$ and pressure is relatively insensitive to bulk composition. There is insufficient temperature variation in our experimental dataset for the behaviour of $\mathrm{Al}^{\text {tot }}$ or $\mathrm{Al}^{\mathrm{iv}}$ to be solely the result of temperature dependence; when $\mathrm{Al}^{\text {iv }}$ is plotted versus temperature (not shown) there is, in fact, a weak negative correlation that in part reflects the tendency for lower pressure experiments to be conducted at higher temperature in accordance with the slope of the water-saturated granite solidus. Note also that $\mathrm{Mg} \#$ does not show any strong correlation with experimental conditions. In both Figs. 5 and 6, it is apparent that amphiboles produced from 
Fig. 6 Relationship between aluminium content of experimental amphiboles and pressure. $\mathbf{a} \mathrm{Al}^{\mathrm{tot}} ; \mathbf{b ~} \mathrm{Al}^{\mathrm{iv}}$. Note that the relationship is not linear but is similar for all three starting materials
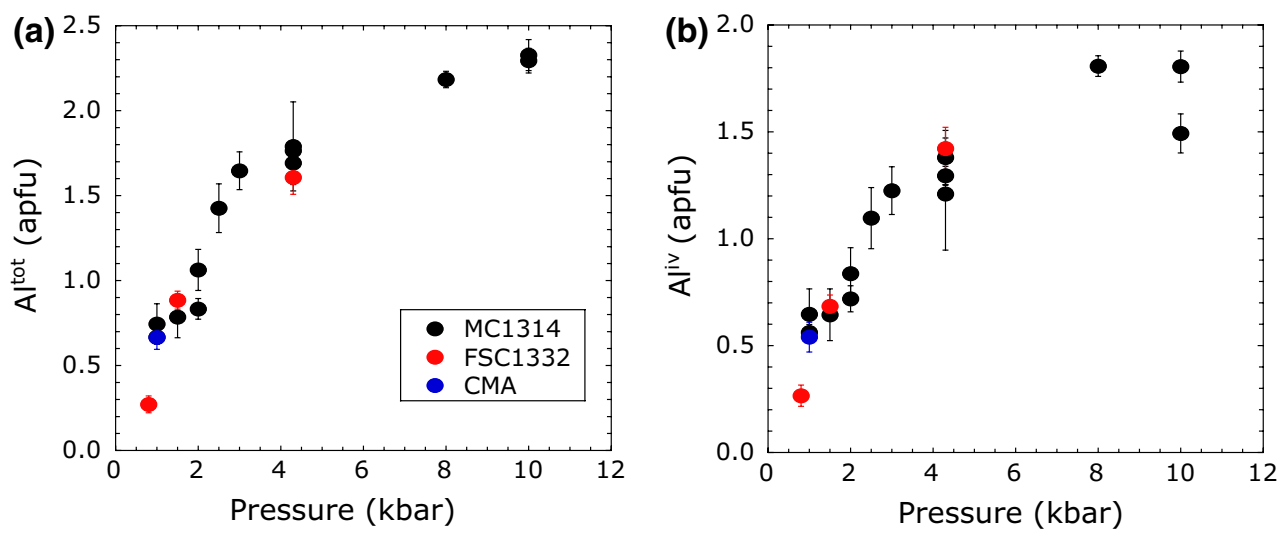

runs at the same pressure and on the same starting material yield amphiboles with very similar composition (Table 5), regardless of the grain size of the starting material (i.e. MC1314 R01 and R08; MC1314 R02 and R10).

\section{Plagioclases}

Experimental plagioclase rim compositions (Table 6) span $\mathrm{An}_{24}$ to $\mathrm{An}_{58}$. Unlike amphiboles, there are clear differences between the compositions of plagioclases from runs using different starting material, with those from FSC1332 runs generally lower in An content than those from MC1314 or CMA (Fig. 7). This highlights the importance of bulk rock $\mathrm{Na} / \mathrm{Ca}$ and $\mathrm{Al}_{2} \mathrm{O}_{3}$ content in controlling plagioclase composition. It is straightforward to exclude relict cores from our analyses of MC1314 and FSC1332 run products because they show the opposite relationship to the experimental plagioclase, i.e. those from FSC1332 starting material have higher An than those from MC1314 (Table 3; Fig. 7). Orthoclase (Or) contents also depend on bulk composition. Or contents are uniformly low $(\leq 3$ mol\%) in all MC1314 and CMA runs, but increase with decreasing pressure in FSC12332 runs from $6 \mathrm{~mol} \%$ at 4.3 kbar to almost $10 \mathrm{~mol} \%$ at $0.8 \mathrm{kbar}$ (Table 6). In terms of intensive variables, there is a slight decrease in An content with decreasing pressure (Fig. 7), but this never overcomes the substantial differences between the different starting materials. Any effect of changing the dissolved water content of the melt on An content, due to changes in pressure, is countered by the influence of changing temperature. For example, Cashman and Blundy (2013) have shown that a temperature change of $10{ }^{\circ} \mathrm{C}$ can change An content by as much as $10 \mathrm{~mol} \%$ for Mt St Helens plagioclase. Again, pairs of runs at similar conditions but with different grain size starting materials (MC1314 R01 and R08), produced plagioclase with An contents that agree within 1 s.d.

For those runs in which both amphibole and plagioclase have been analysed, we have calculated the amphibole-plagioclase temperature using the thermometer of Holland and
Blundy (1994). The temperatures (Table 3) are in reasonable agreement with the experimental temperatures (average absolute deviation, $a a d=70{ }^{\circ} \mathrm{C}$ ), although in three runs the discrepancy is more than $100{ }^{\circ} \mathrm{C}$. The source of this discrepancy is not clear. It was not possible to calculate a temperature for run FSC1332R01 because of the apparent presence of tetrahedral $\mathrm{Fe}^{3+}$.

\section{Fe-Ti oxides}

Four runs contained coexisting ilmenite and magnetite grains with grain sizes sufficiently large for microprobe analysis (Table 7). These pairs enabled us to calculate the equilibrium temperature and $\mathrm{fO}_{2}$ using the methods of Spencer and Lindsley (1981) and Andersen and Lindsley (1988). The agreement with experimental temperatures is very good $\left(\mathrm{aad}=39{ }^{\circ} \mathrm{C}\right)$. The calculated $\mathrm{fO}_{2}$ values for the three CSV runs are in agreement at $\Delta \mathrm{NNO}=0.6$ to $1.0 \mathrm{log}$ units, which is consistent with the composition of the Nimonic pressure vessel; if $\mathrm{Ni}$ mixes ideally in the Nimonic alloy, then the deviation should be $2 \log X_{\mathrm{Ni}}=\Delta \mathrm{NNO}+0.5$. For the single piston cylinder run with coexisting oxides, we calculate $\Delta \mathrm{NNO}=0.0$, indicating that the double-capsule buffering technique was effective and that the experimental charge is at or close to $\mathrm{H}_{2} \mathrm{O}$ saturation; sample $f \mathrm{O}_{2}$ will differ from buffer $f \mathrm{O}_{2}$ by $2 \log a \mathrm{H}_{2} \mathrm{O}$ for water-undersaturated conditions $\left(a \mathrm{H}_{2} \mathrm{O}<1\right)$.

\section{Alkali feldspar}

Alkali feldspars (Table 8) have $\mathrm{Or}$ contents between 71 and $83 \mathrm{~mol} \%$. In three runs, data are available for coexisting alkali feldspar and plagioclase, allowing for a calculation of temperature. Results from the Putirka (2008) formulation are given in Table 3. For runs MC1314R01 and CMA201, the agreement with run temperatures is within $\pm 40{ }^{\circ} \mathrm{C}$. For run MC1314R07, the calculated temperature is higher than expected, although this is a run where the thermocouple broke and true run temperature is not well 


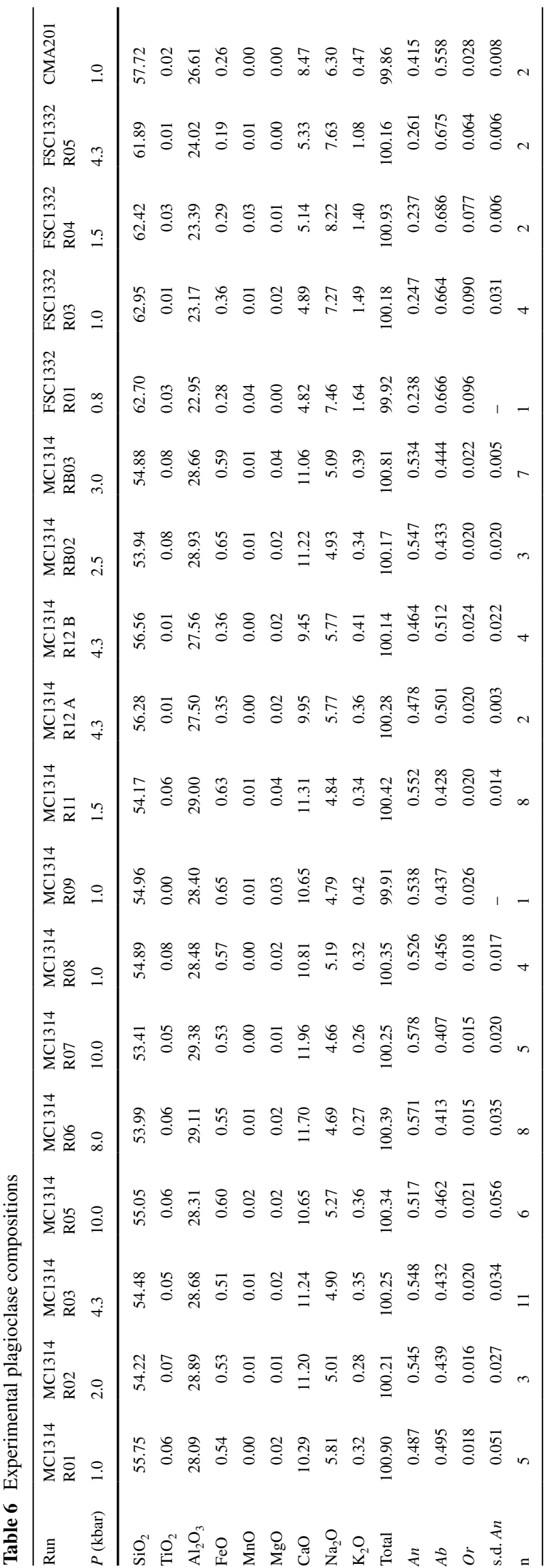

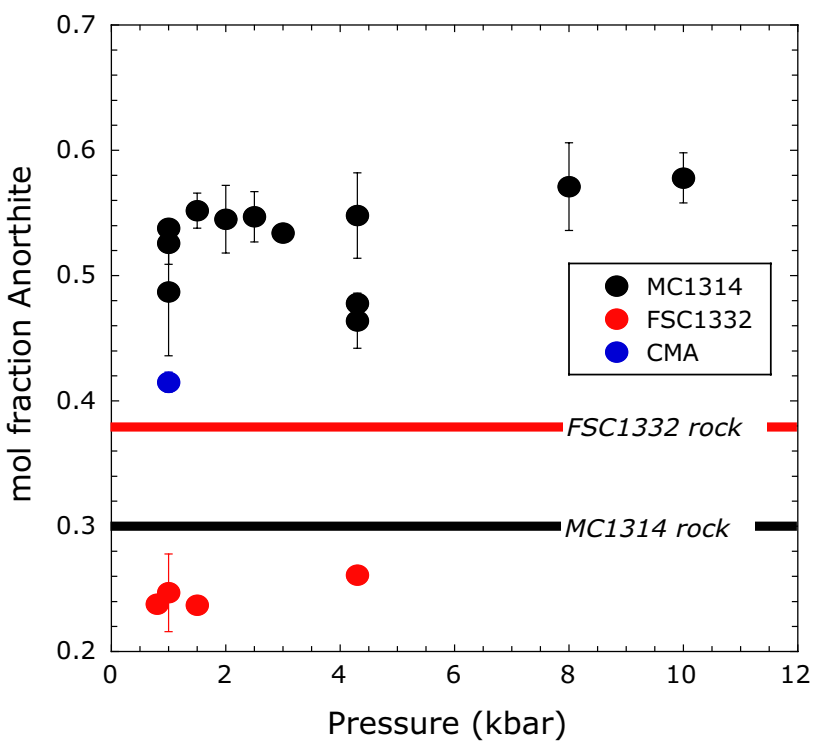

Fig. 7 Plot of molar anorthite (An) content of experimental plagioclase rims versus pressure. Starting composition exercises a much bigger influence on plagioclase composition than pressure. The lack of observed change of An content with pressure within a single bulk composition can be explained by the counteracting effects of temperature and melt $\mathrm{H}_{2} \mathrm{O}$ content. The compositions of plagioclase rims from starting materials MC1314 and FSC1332 (Table 2) are shown as horizontal bars

constrained. According to the Putirka (2008) criteria for two-feldspar equilibrium, the alkali feldspar and plagioclase in MC1314R07 may not be very well equilibrated.

\section{Biotite}

Biotites are annite-rich solid solutions with $\mathrm{Mg \#}$ of $0.51-$ 0.59 and 2.1-2.6 $\mathrm{Al}^{\mathrm{IV}}$ apfu (Table 9). In experiments that contain both biotite and amphibole, there is no consistent relationship between the $\mathrm{Mg \#}$ of the two minerals. Biotites have broadly similar $\mathrm{Cl}$ contents to coexisting amphibole. Although it was not possible to analyse biotites for all runs, there is a striking correlation between the total $\mathrm{Al}$ content of biotite (calculated on the basis of 22 oxygens) and pressure (Fig. 8) suggesting that this mineral may also have potential as a barometer.

\section{Pyroxenes}

Clinopyroxenes (Table 10) are predominantly salites with $>0.9 \mathrm{Ca}$ apfu; the rest are augites. The lowest $\mathrm{Ca}(0.63$ apfu) is from a single run at $1 \mathrm{kbar}$ that exhibits complex intergrowth between pyroxenes and amphibole. Clinopyroxene and orthopyroxene $\mathrm{Al}_{2} \mathrm{O}_{3}$ contents are uniformly low $(<3 \mathrm{wt} \%)$. There is no correlation between $\mathrm{Al}$ or $\mathrm{Na}$ apfu and pressure. 


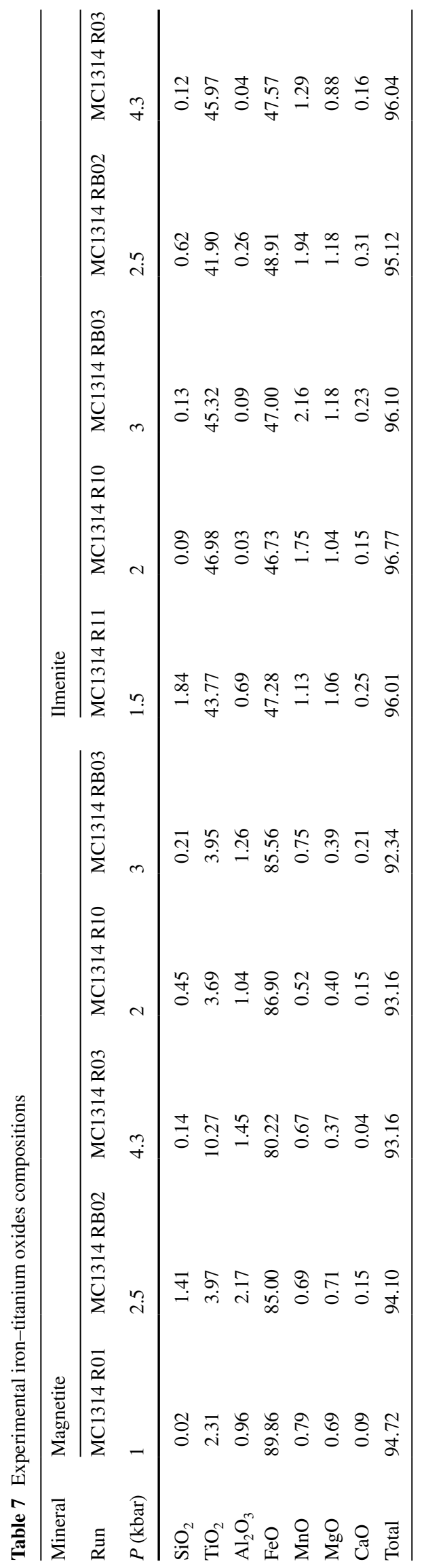

\section{Apatite}

A single apatite grain was large enough for EPMA, from run FSC1332R06. This grain is fluorine-rich (4.3 wt $\%$ ) suggesting that the starting material may also have contained significant, but unknown, fluorine. Fluorine was not routinely measured in other phases, including amphibole and biotite.

\section{Granite emplacement barometry}

\section{Calibration dataset}

Our aim is to develop a barometer that can be used over a wide range of bulk compositions in rocks that contain the requisite buffer assemblage, but without having to constrain the equilibration temperature to be exactly that of the granite solidus, which in most plutonic rocks is very difficult to do. This is reflected in our choice of calibrant data. In addition to our new experimental results presented, we have included experimental data on other low-variance systems, in addition to natural granites where the emplacement pressure is independently constrained with some degree of accuracy. We have chosen not to include the experiments of Schmidt (1992) at pressures high enough to stabilize garnet ( $>14 \mathrm{kbar}$ ) or phengite ( $>13 \mathrm{kbar}$ ) because in both cases it is clear that the change in buffer assemblage, notably the appearance of a new and significant Albearing phase, changes significantly the nature of the $\mathrm{Al}^{\text {tot }}$ versus pressure dependence of other minerals. For the same reasons, we have not included the garnet-bearing $10 \mathrm{kbar}$ experiments of Rutter et al (1989), even though these were designed as a test of the Al-in-hornblende barometer. The presence of epidote in Schmidt (1992) runs above 6 kbar and all Thomas and Ernst's (1990) runs does not appear to

Table 8 Experimental alkali feldspar compositions

\begin{tabular}{lrlrl}
\hline Mineral & \multicolumn{4}{l}{ K-Feldspar } \\
\cline { 2 - 5 } Run & MC1314 R01 & MC1314 R07 & FSC1332 R06 & CMA201 \\
$P$ (kbar) & 1 & 10 & 1 & 1 \\
\hline $\mathrm{SiO}_{2}$ & 64.76 & 63.57 & 64.17 & 65.30 \\
$\mathrm{TiO}_{2}$ & 0.03 & 0.01 & 0.02 & 0.00 \\
$\mathrm{Al}_{2} \mathrm{O}_{3}$ & 18.64 & 19.36 & 19.00 & 19.02 \\
$\mathrm{FeO}$ & 0.29 & 0.33 & 0.31 & 0.14 \\
$\mathrm{MnO}$ & 0.01 & 0.00 & 0.01 & 0.00 \\
$\mathrm{MgO}$ & 0.01 & 0.00 & 0.00 & 0.00 \\
$\mathrm{CaO}$ & 0.10 & 0.53 & 0.32 & 0.17 \\
$\mathrm{Na} 2 \mathrm{O}$ & 1.82 & 1.95 & 1.88 & 3.15 \\
$\mathrm{~K}_{2} \mathrm{O}$ & 14.16 & 13.25 & 13.70 & 11.80 \\
$\mathrm{Total}$ & 99.81 & 98.99 & 99.40 & 99.56 \\
\hline
\end{tabular}


Table 9 Experimental biotite compositions

\begin{tabular}{lccccc}
\hline Mineral & Biotite & \multicolumn{5}{l}{} \\
\cline { 2 - 5 } Run & MC1314 R10 & MC1314 R12A & MC1314 R12B & MC1314 RB02 & MC1314 RB03 \\
$P($ kbar $)$ & 2 & 4.3 & 4.3 & 2.5 & 3 \\
\hline $\mathrm{SiO}_{2}$ & 37.92 & 36.91 & 35.56 & 39.23 & 37.77 \\
$\mathrm{TiO}_{2}$ & 2.57 & 3.46 & 3.10 & 3.81 & 3.20 \\
$\mathrm{Al}_{2} \mathrm{O}_{3}$ & 12.91 & 15.63 & 15.54 & 13.79 & 14.65 \\
$\mathrm{FeO}$ & 19.83 & 16.56 & 18.47 & 18.01 & 19.11 \\
$\mathrm{MnO}$ & 0.23 & 0.06 & 0.12 & 0.27 & 0.31 \\
$\mathrm{MgO}$ & 12.30 & 13.53 & 12.51 & 11.71 & 11.23 \\
$\mathrm{CaO}$ & 0.33 & 0.09 & 0.33 & 0.19 & 0.20 \\
$\mathrm{Na} 2 \mathrm{O}$ & 0.24 & 0.68 & 0.73 & 0.33 & 0.36 \\
$\mathrm{~K}_{2} \mathrm{O}$ & 8.42 & 8.19 & 8.10 & 8.11 & 8.29 \\
$\mathrm{Cl}$ & 0.064 & 0.02 & 0.02 & 0.29 & 0.038 \\
$\mathrm{Total}$ & 94.82 & 95.13 & 94.47 & 95.75 & 95.17
\end{tabular}

have any effect on amphibole $\mathrm{Al}^{\text {tot }}$ and so these experimental data have been included. Beyond these calibration studies we have failed, despite exhaustive searches, to find any other experiments that both (a) contain the appropriate lowvariance assemblage and (b) report analyses of amphiboles. For the experimental data, we adopt uncertainties on experimental temperatures and pressures that are those provided by the authors themselves. Additional data for experimental plagioclases not provided in the original calibration papers were taken from Schmidt (1993) and Johnson and Rutherford (1988).

In order to augment the experimental dataset, we have also included data from the five natural granites used in the original calibration of Hammarstrom and Zen (1986), as these were selected originally on the basis of independent constraints on their emplacement pressures. Moreover, amphibole-plagioclase thermometry of the samples used for their calibration yields temperature close to the granite solidus. To ensure that their weight as calibrants takes into account the fact that they are natural, rather than experimental, samples, we have adopted pressure errors of \pm 0.6 kbar, as suggested by Hammarstrom and Zen (1986) and $\pm 40{ }^{\circ} \mathrm{C}$ for the temperature, in keeping with the uncertainty on the Holland and Blundy (1994) geothermometer. ${ }^{2}$

Ague (1997) uses a thermodynamic evaluation of Equilibrium (1) to estimate the emplacement depth of 18 granitic rocks from the Sierra Nevada Batholith and provides mineral analyses for all samples studied. He demonstrates that the calculated pressures (from 1 to $8 \mathrm{kbar}$ ) are in broad agreement with independent estimates of emplacement depths. His calculated temperatures, from

\footnotetext{
${ }^{2}$ We do not use the calibration data of Hollister et al. (1987) because they do not provide full amphibole chemical analyses or coexisting plagioclase analyses for thermometry.
}

amphibole-plagioclase thermometry, are consistently within $\sim 150{ }^{\circ} \mathrm{C}$ of the water-saturated granite solidus. We have used Ague's (1997) data as part of our calibrant dataset, again with a weighting of $\pm 40{ }^{\circ} \mathrm{C}$ and \pm 0.6 kbar.

Additionally, we have collected our own amphibole data from three McLeod Hill quartz monzonite samples from the Ann Mason area of the Jurassic Yerington Batholith, Nevada (Dilles 1987), all of which have the assemblage: hornblende + biotite + plagioclase + quartz + K-feldspar + apatite + titanite + zircon + FeTi oxides. The Yerington Batholith has been tilted by Basin and Range normal faulting such that it now lies in cross-sectional view, revealing $\mathrm{a} \sim 8 \mathrm{~km}$ section below the palaeosurface at the time of batholith emplacement. This makes the emplacement depth of the granite samples easy to estimate from map view alone (Fig. 3 in Dilles 1987). Our samples (Fig. 9; Table 11) come from palaeodepths of $3.4 \mathrm{~km}$ (FY1307), $4.8 \mathrm{~km}$ (FY1305), and $5.3 \mathrm{~km}$ (FY1301). Assuming a mean rock density of $2750 \mathrm{~kg} / \mathrm{m}^{3}$ for the overburden, this equates to pressures of $0.9,1.3$ and 1.4 kbar, respectively. For each sample, we analysed fresh amphibole rims adjacent to plagioclase; mean compositions are reported in Table 11. The calculated amphibole-plagioclase temperatures (680$700{ }^{\circ} \mathrm{C}$ ) correspond to the low-pressure, water-saturated granite solidus. (A fourth sample (FY1308) from a palaeodepth of $2.8 \mathrm{~km}$ (0.8 kbar) lacked primary magmatic amphibole, showing little evidence that magmatic amphibole had once been present. This suggests that this sample was emplaced at pressures below the minimum pressure limit of magmatic amphibole.) The analysed amphibole rims have mean $\mathrm{Al}^{\text {tot }}$ contents that correlate, within error, with the estimated emplacement pressure. Uncertainty on $\mathrm{Al}^{\text {tot }}$ for each sample is \pm 0.10 to \pm 0.23 apfu. These three samples are also used for calibration with temperature uncertainty of $\pm 40{ }^{\circ} \mathrm{C}$ and pressure uncertainty of $0.2 \mathrm{kbar}$. 


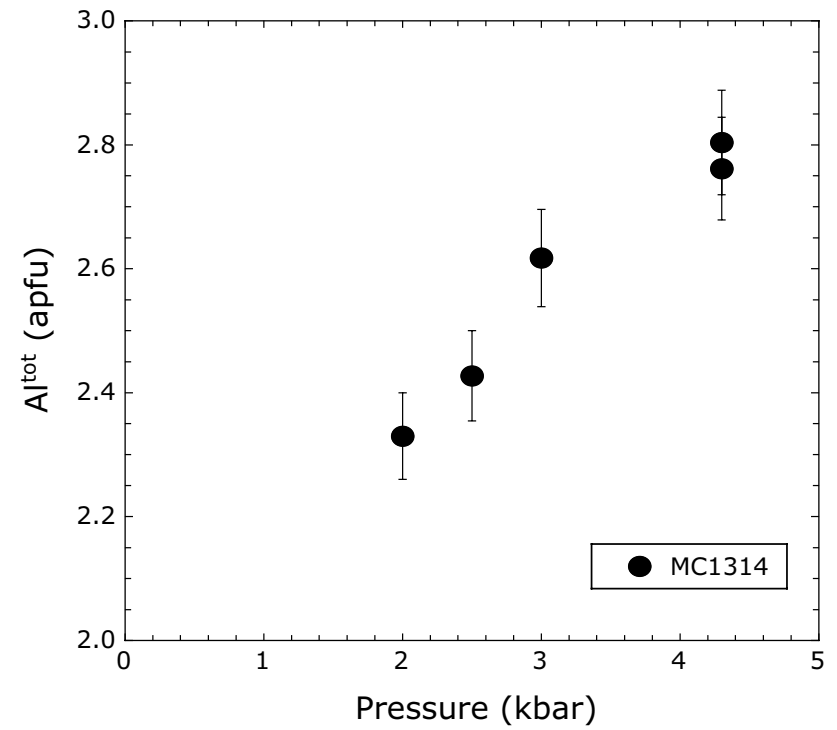

Fig. 8 Relationship between $\mathrm{Al}^{\text {tot }}$ in experimental biotites and pressure in five MC1314 runs

The latter value is lower than used for other natural samples because the only uncertainties are the measured map distance and the mean crustal density.

Figure 1 shows that bulk compositions of the entire calibrant dataset cover a significant fraction of the compositional variation observed in natural granitoids (tonalite to granite). Most of the previous calibrations of the barometer have been restricted to compositions between 55 and 70 wt $\% \mathrm{SiO}_{2}$ and 15 and 20 wt $\% \mathrm{Al}_{2} \mathrm{O}_{3}$ (Fig. 1a); our experimental dataset expands this range up to $76 \mathrm{wt} \%$ $\mathrm{SiO}_{2}$. Thus, we advise that our calibration of the barometer should only be applied to low-variance calc-alkaline granitoids in the compositional range 55 and $80 \mathrm{wt} \% \mathrm{SiO}_{2}$ and 10 and $20 \mathrm{wt} \% \mathrm{Al}_{2} \mathrm{O}_{3}$.

The $P-T$ range of the experimental data used to calibrate the barometer, along with their uncertainties, is plotted in Fig. 10a. We also show the water-saturated haplogranite solidus, parameterised from Fig. 2 of Holtz and Johannes (1994) as:

$T_{\text {solidus }}\left({ }^{\circ} \mathrm{C}\right)=626+\frac{118.46}{P(\text { kbar })+0.357}$

Most of the new experiments reported here, with the exception of four at higher temperatures, and all of those from Schmidt (1992) lie within $20{ }^{\circ} \mathrm{C}$ of the solidus. The experiments of Thomas and Ernst (1990) and Johnson and Rutherford (1989) are systematically displaced to higher temperature, as previously noted by Anderson and Smith (1995); with one exception these are $\leq 100{ }^{\circ} \mathrm{C}$ above the haplogranite solidus. Finally, the natural data from Ague (1997) and Hammarstrom and Zen (1986) and the Yerington Batholith (Table 11) span the temperatures in between

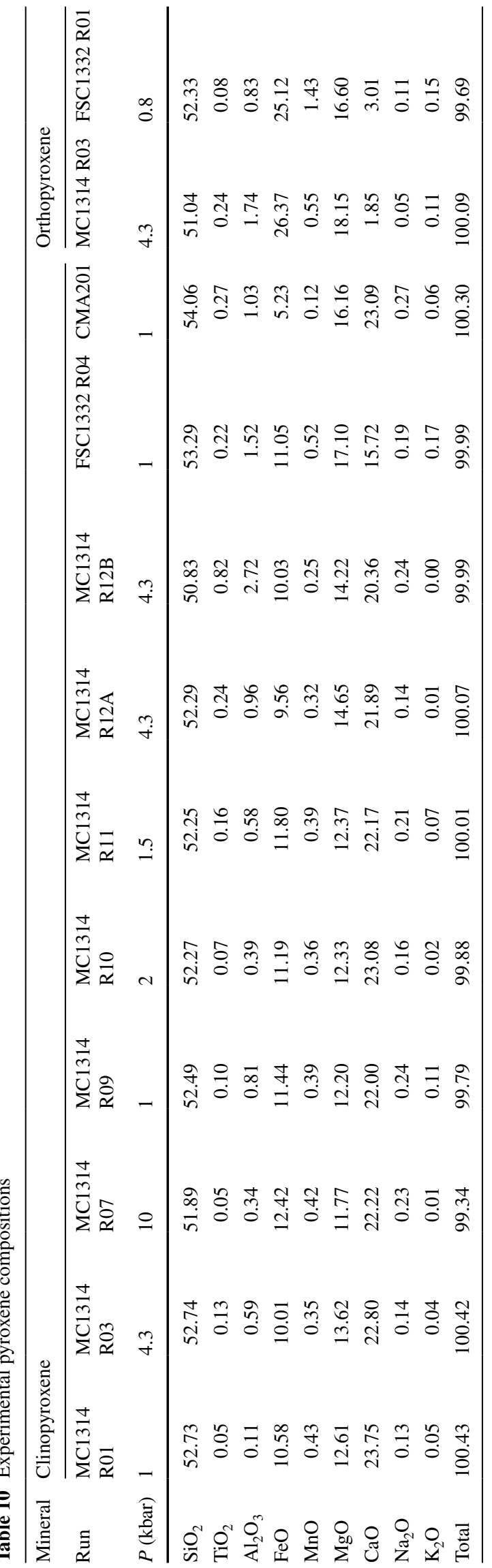



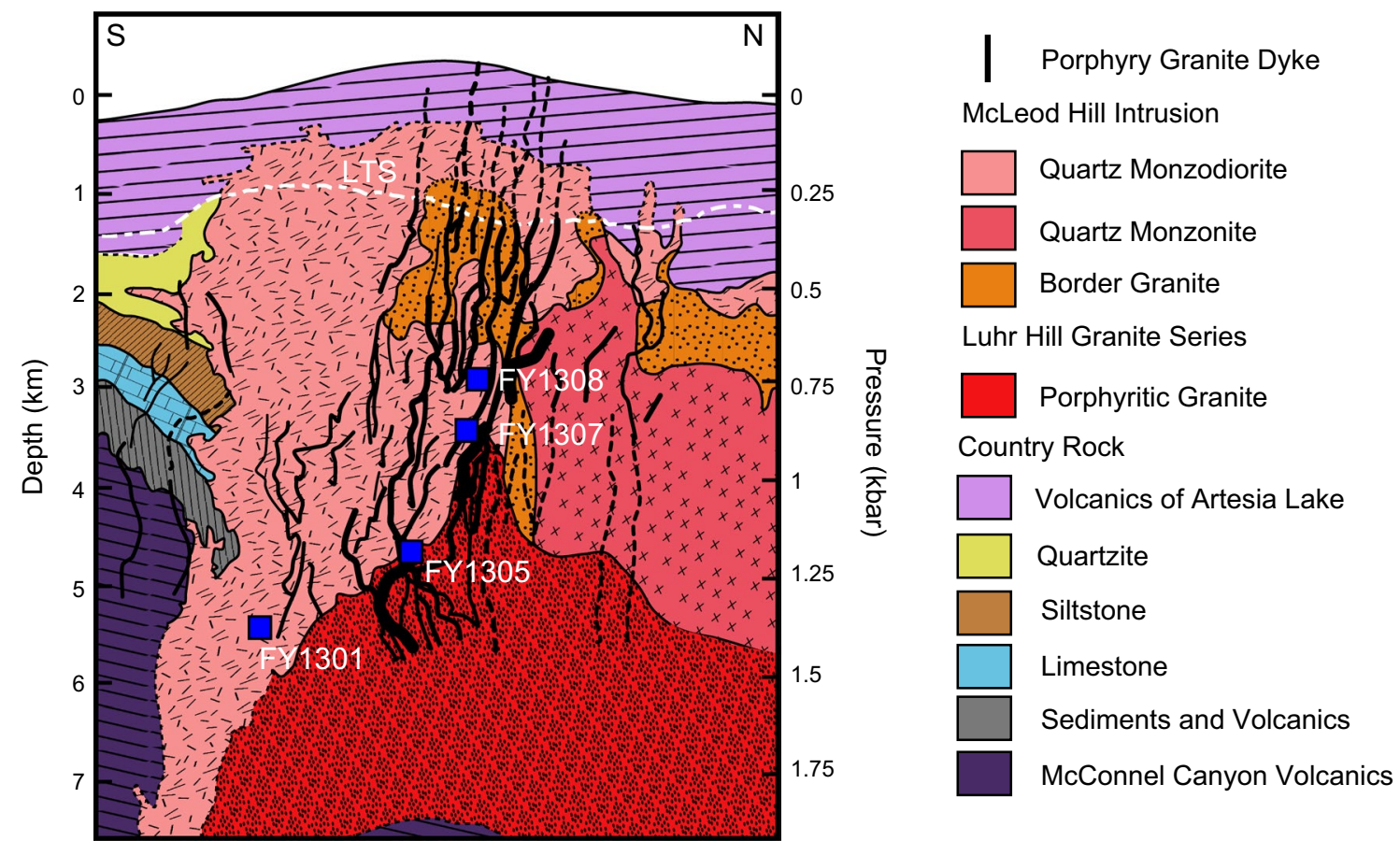

Fig. 9 Sketch map of the Yerington Batholith, Nevada, adapted after Dilles (1987), showing the locations of the samples collected. FY1301, 1305 and 1307 were used as barometer calibrants; FY1308 lacks magmatic amphibole; FY1313 was too altered to recover reli-

the solidus and the higher temperature experiments. All but one of the calibrant data lie in the temperature range $725 \pm 75^{\circ} \mathrm{C}$.

Also on Fig. 10a, we show the stability curve of actinolite, $\mathrm{Ca}_{2} \mathrm{Fe}_{5} \mathrm{Si}_{8} \mathrm{O}_{22}(\mathrm{OH})_{2}$ from Lledo and Jenkins (2008) who investigated experimentally the low pressure $(<5 \mathrm{kbar})$ breakdown of the tremolite-actinolite solid solution series to pyroxenes and quartz via the reaction:

$$
\begin{aligned}
& \underset{\text { actinolite }}{\mathrm{Ca}_{2} \mathrm{Fe}_{5} \mathrm{Si}_{8} \mathrm{O}_{22}(\mathrm{OH})_{2}} \\
& \quad=\underset{\text { clinopyroxene }}{\mathrm{CaFeSi}_{2} \mathrm{O}_{6}}+\underset{\text { orthopyroxene }}{1.5 \mathrm{Fe}_{2} \mathrm{Si}_{2} \mathrm{O}_{6}}+\underset{\text { quartz }}{\mathrm{SiO}_{2}}+\underset{\text { vapour }}{\mathrm{H}_{2} \mathrm{O}}
\end{aligned}
$$

With increasing temperature Reaction (4) proceeds to the right (Fig. 10a). For the equivalent reaction involving tremolite (not shown in Fig. 10a), stability is displaced to lower temperatures; at $1 \mathrm{kbar}$ tremolite-breakdown is $\sim 350{ }^{\circ} \mathrm{C}$ below actinolite breakdown. The significance of this curve is that the actinolite-tremolite solid solution involves clinoamphiboles with zero aluminium content. The stability curve of actinolite, the most stable of the solid solution series, thus defines the lowest pressure conditions at which members of the clino-amphibole group can occur. The intersection of the actinolite stability curve with the watersaturated haplogranite solidus therefore marks the lowest pressure at which, theoretically at least, an amphibole can able magmatic amphibole analyses. Depth on the left-hand axis is measured relative to the Jurassic palaeosurface. LTS denotes lower tertiary erosion surface

occur in magmatic rocks. Following Lledo and Jenkins (2008) and Fig. 10a, this pressure is $0.5 \mathrm{kbar}$ and $800{ }^{\circ} \mathrm{C}$. Interestingly, these conditions are very similar to the lowest pressure experimental amphiboles recorded from natural compositions $\left(0.49 \mathrm{kbar}, 813{ }^{\circ} \mathrm{C}\right)$ by Sato et al (1999). Note, however, that these were cooling-rate, rather than phase equilibrium, experiments, conducted on dacite bulk compositions that did not yield the requisite low-variance buffer assemblage required for our calibration dataset.

The calibration dataset contains a wide range of amphi-

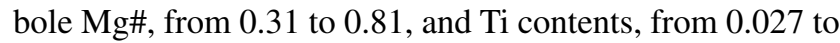
$0.345 \mathrm{apfu}$. There is a weak tendency for $\mathrm{Mg} \#$ to increase with decreasing pressure (not shown) although bulk composition also plays a role. There is complete overlap in terms of $\mathrm{Mg} \#$ and $\mathrm{Ti}$ between the experimental and the natural amphiboles. In terms of plagioclase composition, the calibration dataset involves a very wide range in composition from $\mathrm{An}_{15}$ to $\mathrm{An}_{76}$ with no correlation with intensive variables (Fig. 10b).

\section{Aluminium-in-hornblende}

The calibration amphiboles display a strong and consistent dependence of $\mathrm{Al}^{\text {tot }}$ on pressure (Fig. 10c) despite the wide range of bulk compositions, plagioclase compositions and experimental temperatures, relative to the water-saturated 
Table 11 Amphibole compositions from the Yerington Batholith, Nevada

\begin{tabular}{|c|c|c|c|c|c|c|}
\hline Sample & \multicolumn{2}{|c|}{ FY1301 } & \multicolumn{2}{|c|}{ FY1307 } & \multicolumn{2}{|l|}{ FY1305 } \\
\hline Latitude & \multicolumn{2}{|c|}{$38^{\circ} 57.666^{\prime} \mathrm{N}$} & \multicolumn{2}{|c|}{$38^{\circ} 58.832^{\prime} \mathrm{N}$} & \multicolumn{2}{|c|}{$38^{\circ} 58.668^{\prime} \mathrm{N}$} \\
\hline Longitude & \multicolumn{2}{|c|}{$119^{\circ} 13.864^{\prime} \mathrm{W}$} & \multicolumn{2}{|c|}{$119^{\circ} 15.060^{\prime} \mathrm{W}$} & \multicolumn{2}{|c|}{$119^{\circ} 14.373^{\prime} \mathrm{W}$} \\
\hline Depth $(\mathrm{km})^{\mathrm{a}}$ & \multicolumn{2}{|l|}{5.3} & \multicolumn{2}{|l|}{3.4} & \multicolumn{2}{|l|}{4.8} \\
\hline \multirow[t]{2}{*}{$P$ (kbar) } & \multicolumn{2}{|l|}{1.4} & \multicolumn{2}{|l|}{0.9} & \multicolumn{2}{|l|}{1.3} \\
\hline & Mean & s.d. & Mean & s.d. & Mean & s.d. \\
\hline $\mathrm{SiO}_{2}$ & 49.17 & 0.89 & 49.00 & 1.77 & 50.72 & 1.29 \\
\hline $\mathrm{TiO}_{2}$ & 0.57 & 0.20 & 0.97 & 0.44 & 0.62 & 0.21 \\
\hline $\mathrm{Al}_{2} \mathrm{O}_{3}$ & 4.99 & 0.60 & 5.04 & 1.29 & 4.22 & 0.93 \\
\hline $\mathrm{FeO}$ & 13.27 & 0.70 & 12.37 & 0.69 & 11.72 & 0.93 \\
\hline $\mathrm{MnO}$ & 0.45 & 0.03 & 0.41 & 0.04 & 0.41 & 0.05 \\
\hline $\mathrm{MgO}$ & 14.00 & 0.45 & 14.59 & 0.85 & 15.97 & 0.88 \\
\hline $\mathrm{CaO}$ & 12.25 & 0.22 & 12.07 & 0.24 & 12.20 & 0.27 \\
\hline $\mathrm{Na}_{2} \mathrm{O}$ & 0.73 & 0.14 & 0.85 & 0.24 & 0.95 & 0.24 \\
\hline $\mathrm{K}_{2} \mathrm{O}$ & 0.45 & 0.09 & 0.53 & 0.18 & 0.44 & 0.13 \\
\hline $\mathrm{Cl}$ & 0.07 & 0.01 & 0.11 & 0.05 & 0.06 & 0.02 \\
\hline Total & 95.94 & 0.87 & 95.95 & 0.50 & 100.00 & 0.01 \\
\hline $\mathrm{Si}$ & 7.282 & 0.136 & 7.246 & 0.213 & 7.341 & 0.134 \\
\hline $\mathrm{Al}^{\mathrm{IV}}$ & 0.718 & 0.136 & 0.754 & 0.213 & 0.654 & 0.136 \\
\hline Sum T & 8.000 & 0.000 & 8.000 & 0.000 & 7.995 & 0.013 \\
\hline $\mathrm{Al}^{\mathrm{VI}}$ & 0.151 & 0.049 & 0.123 & 0.053 & 0.065 & 0.045 \\
\hline $\mathrm{Ti}$ & 0.064 & 0.022 & 0.108 & 0.049 & 0.068 & 0.023 \\
\hline $\mathrm{Fe}^{3+}$ & 0.218 & 0.086 & 0.163 & 0.067 & 0.212 & 0.055 \\
\hline $\mathrm{Mg}$ & 1.567 & 0.063 & 1.607 & 0.092 & 1.655 & 0.067 \\
\hline $\mathrm{Fe}^{2+}$ & 0.000 & 0.000 & 0.000 & 0.000 & 0.000 & 0.000 \\
\hline Sum D & 2.000 & 0.000 & 2.000 & 0.000 & 2.000 & 0.000 \\
\hline $\mathrm{Mg}$ & 1.543 & 0.058 & 1.629 & 0.099 & 1.805 & 0.117 \\
\hline $\mathrm{Fe}^{2+}$ & 1.420 & 0.061 & 1.361 & 0.104 & 1.188 & 0.121 \\
\hline $\mathrm{Mn}$ & 0.037 & 0.016 & 0.010 & 0.017 & 0.007 & 0.013 \\
\hline Sum C & 3.000 & 0.000 & 3.000 & 0.000 & 3.000 & 0.000 \\
\hline $\mathrm{Mg}$ & 0.000 & 0.000 & 0.000 & 0.000 & 0.000 & 0.000 \\
\hline $\mathrm{Fe}^{2+}$ & 0.000 & 0.000 & 0.000 & 0.000 & 0.014 & 0.028 \\
\hline $\mathrm{Mn}$ & 0.020 & 0.017 & 0.042 & 0.017 & 0.044 & 0.013 \\
\hline $\mathrm{Ca}$ & 1.944 & 0.029 & 1.912 & 0.030 & 1.892 & 0.032 \\
\hline $\mathrm{Na}$ & 0.036 & 0.012 & 0.046 & 0.012 & 0.049 & 0.032 \\
\hline Sum B & 2.000 & 0.000 & 2.000 & 0.000 & 2.000 & 0.000 \\
\hline $\mathrm{Na}$ & 0.172 & 0.044 & 0.198 & 0.055 & 0.217 & 0.059 \\
\hline $\mathrm{K}$ & 0.085 & 0.018 & 0.101 & 0.034 & 0.082 & 0.025 \\
\hline Sum A & 0.257 & 0.054 & 0.299 & 0.086 & 0.299 & 0.077 \\
\hline Total & 15.257 & 0.054 & 15.299 & 0.086 & 13.294 & 0.077 \\
\hline $\mathrm{Al}^{\mathrm{tot}}$ & 0.869 & 0.104 & 0.876 & 0.227 & 0.719 & 0.164 \\
\hline Mg\# & 0.65 & 0.02 & 0.68 & 0.02 & 0.71 & 0.03 \\
\hline$X \mathrm{An}_{\text {plag }}$ & 0.27 & 0.25 & 0.15 & & & \\
\hline$X \mathrm{Ab}_{\text {plag }}$ & 0.72 & 0.74 & 0.85 & & & \\
\hline $\mathrm{T}_{\mathrm{A}}(\mathrm{hbpl})^{\mathrm{b}}{ }^{\circ} \mathrm{C}$ & 679 & 699 & 694 & & & \\
\hline
\end{tabular}

${ }^{\text {a }}$ Distance to palaeosurface according to map of Dilles (1987)

b Hornblende-plagioclase temperature from Holland and Blundy (1994) 


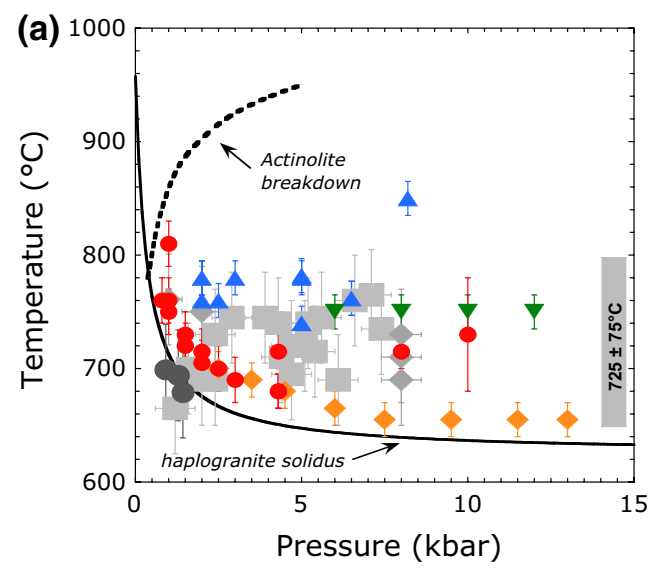

(c)

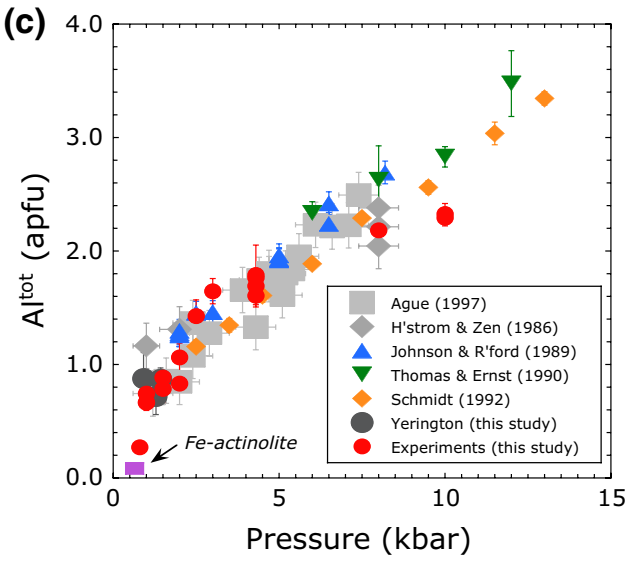

Fig. 10 Characteristics of the amphibole dataset used for calibration. Experimental data are shown with coloured symbols; natural data with grey symbols. HandZ is Hammarsrom and Zen; TandE is Thomas and Ernst; JandR is Johnson and Rutherford; Schm. is Schmidt (1992). a Variation in temperature and pressure for the amphiboles used. For the experimental data, these are the experimental run conditions; for the natural data the $P-T$ conditions are estimated as described in the text. 1 s.d. uncertainties are plotted. The solid line is the water-saturated haplogranite solidus from Eq. (3); the broken line is the Fe-actinolite stability curve from Lledo and Jenkins (2008). The grey bar denotes the temperature range $725 \pm 75^{\circ} \mathrm{C}$ that

haplogranite solidus. Moreover, the close agreement of the Johnson and Rutherford data to the overall trend suggests that the effect of $X \mathrm{H}_{2} \mathrm{O}=0.75$ (rather than 1.0) and the consequent slightly higher temperatures are subsumed by the overall scatter of the data due, for example, to bulk compositional variation. The same relationship is observed in both experimental and natural data, giving us confidence that both types of data can be used to provide a calibration of the barometer provided that proper account is taken of the different uncertainties inherent in natural versus experimental data. There are surprisingly few outliers to the overall trend. The most noticeable are those at $10 \mathrm{kbar}$ from this study, where the consequences of $\mathrm{XH}_{2} \mathrm{O}<1$ may have an effect. Note also that one of the $10 \mathrm{kbar}$ runs (MC1314R05) lacks alkali feldspar and quartz, demonstrating the

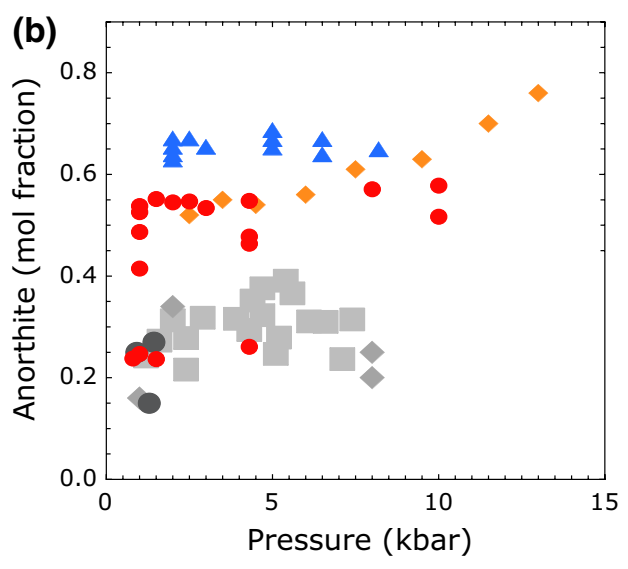

encompasses all but one of the data points used. b Variation in plagioclase rims compositions for the same dataset. Plagioclases from this study cover three different starting materials (see Fig. 7). c Variation in $\mathrm{Al}^{\text {tot }}$ with pressure. Also shown in purple is the intersection of the Fe-actinolite stability curve with the water-saturated haplogranite solidus from (a). 1 s.d. uncertainties in $\mathrm{Al}^{\text {tot }}$ for the natural amphiboles are set arbitrarily at 0.2 apfu, representative of the values we obtain for the Yerington amphiboles in Table 11. 1 s.d. uncertainties for the published experimental amphiboles are those presented by the authors or arbitrarily assigned as 0.1 apfu for Johnson and Rutherford (1989)

importance of both phases in the buffer assemblage. For either or both of these reasons, we do not use our two 10 kbar runs for barometer calibration purposes.

One striking feature of Fig. 10c is the tendency of the data to curve towards the pressure axis at low pressures. Our single experimental datum at $0.8 \mathrm{kbar}$, very close to the limit of amphibole stability in our bulk compositions, follows this curvature, suggesting that amphiboles with very low $\mathrm{Al}^{\text {tot }}$ contents characterise the granite solidus at low, but non-zero pressures. This behaviour is not predicted by any of the existing barometer equations which all return a negative pressure at $\mathrm{Al}^{\mathrm{tot}}=0$. The intersection of the amphibole trend with a non-zero pressure is entirely consistent with the intersection of the actinolite breakdown curve with the haplogranite solidus (Fig. 10a) which 


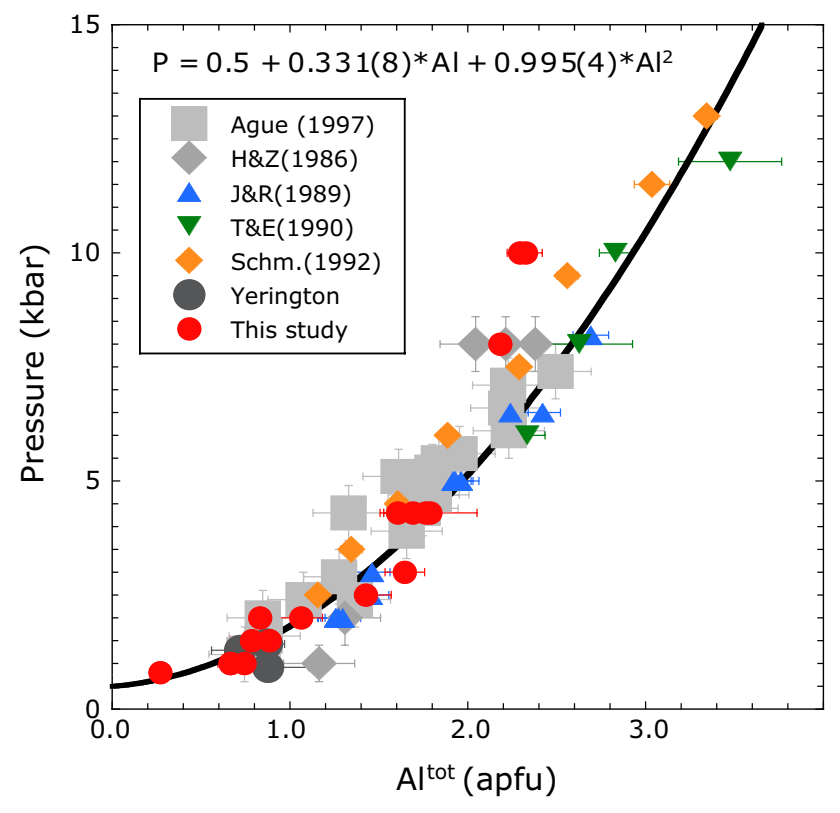

Fig. 11 New Al-in-hornblende barometer calibration using the experimental and natural data presented in Fig. 10. The solid line shows the calibration curve, as given in Eq. (5). The $10 \mathrm{kbar}$ experimental data from this study are plotted, but excluded from the calibration fit

we argue is the minimum (theoretical) pressure at which Al-free amphibole may co-exist with silicate melt (Lledo and Jenkins 2008). In nature Al-free actinolite is unlikely to coexist with Al-bearing haplogranite melt, i.e. a small amount of the $\mathrm{Al}$ will partition from the melt into the crystal. Nonetheless, we would argue that 0.5 kbar represents a much more realistic pressure for Al-free amphibole than negative pressure and, moreover, is consistent with experimental data for the actinolite-tremolite solid solution. A challenge is to find natural, amphibole-bearing granitic rocks emplaced at pressures $<1 \mathrm{kbar}$ to further refine the low-pressure curvature.

The strong dependence of $\mathrm{Al}^{\text {tot }}$ on pressure and the curvature of this relationship from $\leq 3$ to $\sim 0.5 \mathrm{kbar}$ at zero $\mathrm{Al}^{\text {tot }}$ justifies a re-calibration of the Al-in-hornblende geobarometer that describes this low-pressure behaviour and so better recovers emplacement pressures in shallow intrusions. In Fig. 11, we show the calibration plot of pressure versus $\mathrm{Al}^{\text {tot }}$. The relationship is clearly not linear. We have fitted a weighted, second-order polynomial least squares regression to the data. Weighting was according to the uncertainties in the calibration dataset described above. We set the intercept at $0.5 \mathrm{kbar}$, following the observation that the actinolite stability curve crosses the haplogranite solidus at this pressure (Fig. 10a, c). Allowing the intercept to vary freely leads to values that are slightly lower than $0.5 \mathrm{kbar}$, but have large uncertainty. The resulting Al-in-hornblende barometer calibration is:

$$
P(\text { kbar })=0.5+0.331(8) \times \mathrm{Al}^{\mathrm{tot}}+0.995(4) \times\left(\mathrm{Al}^{\mathrm{tot}}\right)^{2}
$$

where $\mathrm{Al}^{\mathrm{tot}}$ is the total amphibole $\mathrm{Al}$ content in apfu and the figures in parentheses are 1 s.d. on the fit parameter expressed in terms of least significant digits. This equation recovers all of the input data, excluding the persistent 10 kbar outliers from this study identified above, to an aad of $0.60 \mathrm{kbar}$, which is comparable to previous calibrations, e.g. Schmidt (1992), that were based on a single bulk composition across a smaller pressure range. As noted above, an uncertainty of $\geq 0.6 \mathrm{kbar}$ will accrue with all existing barometer calibrations simply because the typical standard deviation on the mean $\mathrm{Al}^{\text {tot }}$ from a population of natural amphibole rims in a sample of granite is rarely less than 0.12 apfu (cf. Hollister et al. 1987) and the calibration slope is $\sim 5$. The residuals between known and calculated pressures from Eq. (5) for our calibrant data show no correlation with any compositional parameter, including plagioclase An content, or temperature. The residuals do, however, increase with increasing pressure. It is therefore more appropriate to consider a relative error in pressure rather than an aad. The relative error is $\pm 16 \%$ relative for the entire dataset. We consider that this represents the best realistic barometer calibration given the inherent uncertainty on mean natural amphibole rim compositions, the difficulty of establishing that amphiboles crystallised at the solidus, rather than tens of degrees above. Our barometer is applicable across a wide bulk compositional range, provided that amphibole-plagioclase temperatures are $725 \pm 75{ }^{\circ} \mathrm{C}$ and the appropriate mineral assemblage is present locally in the rock.

Acknowledgments This research was supported through funds from BHP Billiton. JB acknowledges receipt of a Wolfson Research Merit Award from the Royal Society and a Moore Scholarship from the California Institute of Technology where this work was written up. We are grateful to S. Kearns and R. Hinton for assistance, respectively, with EPMA and SIMS analyses, and V. Matjuschkin for help in the high-pressure laboratory. We thank M. van Zalinge for providing two of the starting materials, and both M. van Zalinge and R. Perkins for providing unpublished whole rock data. We greatly appreciate the assistance of J. Dilles in the Yerington Batholith, Nevada, where three of the calibration samples were collected. The paper benefited greatly from the constructive reviews of C. F. Miller, J. J. Ague and an anonymous reviewer as well as the careful editorial handling of G. Moore.

Open Access This article is distributed under the terms of the Creative Commons Attribution 4.0 International License (http://creativecommons.org/licenses/by/4.0/), which permits unrestricted use, distribution, and reproduction in any medium, provided you give appropriate credit to the original author(s) and the source, provide a link to the Creative Commons license, and indicate if changes were made. 


\section{References}

Ague JJ (1997) Thermodynamic calculation of emplacement pressures for batholithic rocks, California: implications for the aluminum-in-hornblende barometer. Geology 25(6):563-566

Ague JJ, Brimhall GH (1988a) Regional variations in bulk chemistry, mineralogy, and the compositions of mafic and accessory minerals in the batholiths of California. Geol Soc Am Bull 100(6):891-911

Ague JJ, Brimhall GH (1988b) Magmatic arc asymmetry and distribution of anomalous plutonic belts in the batholiths of California: effects of assimilation, crustal thickness, and depth of crystallization. Geol Soc Am Bull 100(6):912-927

Andersen DJ, Lindsley DH (1988) Internally consistent solution models for Fe-Mg-Mn-Ti oxides. Am Mineral 73:714-726

Anderson JL (1996) Status of thermobarometry in granitic batholiths. Trans R Soc Edin Earth 87(1-2):125-138

Anderson JL, Smith DR (1995) The effects of temperature and $\mathrm{fO}_{2}$ on the Al-in-hornblende barometer. Am Mineral 80:549-559

Anderson JL, Barth AP, Wooden JL, Mazdab F (2008) Thermometers and thermobarometers in granitic systems. Rev Mineral Geochem 69(1):121-142

Blundy J, Cashman KV (2001) Ascent-driven crystallisation of dacite magmas at Mount St. Helens, 1980-1986. Contrib Miner Petrol 140:631-650

Blundy JD, Holland TJ (1990) Calcic amphibole equilibria and a new amphibole-plagioclase geothermometer. Contrib Miner Petrol 104(2):208-224

Brooker R, Holloway JR, Hervig R (1998) Reduction in piston-cylinder experiments: the detection of carbon infiltration into platinum capsules. Am Mineral 83:985-994

Cashman K, Blundy J (2013) Petrological cannibalism: the chemical and textural consequences of incremental magma body growth. Contrib Miner Petrol 166(3):703-729

Dilles JH (1987) Petrology of the Yerington Batholith, Nevada; evidence for evolution of porphyry copper ore fluids. Econ Geol 82(7):1750-1789

Erdmann S, Martel C, Pichavant M, Kushnir A (2014) Amphibole as an archivist of magmatic crystallization conditions: problems, potential, and implications for inferring magma storage prior to the paroxysmal 2010 eruption of Mount Merapi, Indonesia. Contrib Miner Petrol 167(6):1-23

Ferry JM (1985) Hydrothermal alteration of tertiary igneous rocks from the Isle of Skye, northwest Scotland. II Granites. Contrib Mineral Petrol 91(3):283-304

Ghiorso MS, Gualda GA (2015) $\mathrm{An}_{2} \mathrm{O}-\mathrm{CO}_{2}$ mixed fluid saturation model compatible with rhyolite-MELTS. Contrib Mineral Petrol 169(6): $1-30$

Hammarstrom JM, Zen EA (1986) Aluminum in hornblende; an empirical igneous geobarometer. Am Mineral 71(11-12):1297-1313

Holland T, Blundy J (1994) Non-ideal interactions in calcic amphiboles and their bearing on amphibole-plagioclase thermometry. Contrib Mineral Petrol 116(4):433-447

Hollister LS, Grissom GC, Peters EK, Stowell HH, Sisson VB (1987) Confirmation of the empirical correlation of $\mathrm{Al}$ in hornblende with pressure of solidification of calc-alkaline plutons. Am Mineral 72(3-4):231-239

Holtz F, Johannes W (1994) Maximum and minimum water contents of granitic melts: implications for chemical and physical properties of ascending magmas. Lithos 32(1):149-159

Humphreys M, Kearns SL, Blundy JD (2006) SIMS investigation of electron-beam damage to hydrous, rhyolitic glasses: implications for melt inclusion analysis. Am Mineral 91(4):667-679
Johannes W, Holtz F (1996) Petrogenesis and experimental petrology of granitic rocks, 335th edn. Springer, Berlin, p 330

Johannes W, Bell PM, Mao HK, Boettcher AL, Chipman DW, Hays JF, Seifert F (1971) An interlaboratory comparison of piston-cylinder pressure calibration using the albite-breakdown reaction. Contrib Miner Petrol 32(1):24-38

Johnson MC, Rutherford MJ (1988) Experimentally determined conditions in the Fish Canyon Tuff, Colorado, magma chamber. J Petrol 30:711-737

Johnson MC, Rutherford MJ (1989) Experimental calibration of the aluminum-in-hornblende geobarometer with application to Long Valley caldera (California) volcanic rocks. Geology 17(9):837-841

Keppler H (1989) The influence of the fluid phase composition on the solidus temperatures in the haplogranite system NaAl$\mathrm{Si}_{3} \mathrm{O}_{8}-\mathrm{KAlSi}_{3} \mathrm{O}_{8}-\mathrm{SiO}_{2}-\mathrm{H}_{2} \mathrm{O}-\mathrm{CO}_{2}$. Contrib Mineral Petrol 102(3):321-327

Leake BE, Woolley AR, Birch WD, Burke EA, Ferraris G, Grice JD, Hawthorne FC, Kisch HJ, Krivovichev VG, Schumacher JC, Stephenson NC (2003) Nomenclature of amphiboles: additions and revisions to the International Mineralogical Association's 1997 recommendations. Can Miner 41(6):1355-1362

Lledo HL, Jenkins DM (2008) Experimental investigation of the upper thermal stability of Mg-rich actinolite; implications for Kiruna-type iron deposits. J Petrol 49(2):225-238

McDade P, Wood BJ, Van Westrenen W, Brooker R, Gudmundsson G, Soulard H, Najorka J, Blundy J (2002) Pressure corrections for a selection of piston-cylinder cell assemblies. Mineral Mag 66(6):1021-1028

McIntosh IM, Llewellin EW, Humphreys MCS, Nichols ARL, Burgisser A, Schipper CI, Larsen JF (2014) Distribution of dissolved water in magmatic glass records growth and resorption of bubbles. Earth Planet Sci Lett 401:1-11

Mills RD, Glazner AF (2013) Experimental study on the effects of temperature cycling on coarsening of plagioclase and olivine in an alkali basalt. Contrib Mineral Petrol 166(1):97-111

Paillat O, Elphick SC, Brown WL (1992) The solubility of water in NaAlSi3O8 melts: a re-examination of $\mathrm{Ab}-\mathrm{H}_{2} \mathrm{O}$ phase relationships and critical behaviour at high pressures. Contrib Miner Petrol 112(4):490-500

Pichavant M, Costa F, Burgisser A, Scaillet B, Martel C, Poussineau S (2007) Equilibration scales in silicic to intermediate magmasimplications for experimental studies. J Petrol 48(10):1955-1972

Pistone M, Blundy JD, Brooker RA (2016) Textural consequences of interaction between hydrous mafic and felsic magmas: an experimental study. Contrib Mineral Petrol. doi:10.1007/ s00410-015-1218-4

Putirka K (2008) Thermometers and barometers for volcanic systems. In: Putirka K, Tepley F (eds) Minerals, inclusions and volcanic processes, Rev Mineral Geochem 69:61-120

Putirka K (2016) Amphibole thermometers and barometers for igneous systems and some implications for eruption mechanisms of felsic magmas at arc volcanoes. Am Mineral 101(4):841-858

Ridolfi F, Renzulli A (2012) Calcic amphiboles in calc-alkaline and alkaline magmas: thermobarometric and chemometric empirical equations valid up to $1130{ }^{\circ} \mathrm{C}$ and $2.2 \mathrm{GPa}$. Contrib Mineral Petrol 163:877-895

Ridolfi F, Renzulli A, Puerini M (2010) Stability and chemical equilibrium of amphibole in calc-alkaline magmas: an overview, new thermobarometric formulations and application to subductionrelated volcanoes. Contrib Mineral Petrol 160:45-66

Rutter MJ, Van der Laan SR, Wyllie PJ (1989) Experimental data for a proposed empirical igneous geobarometer: aluminum in hornblende at 10 kbar pressure. Geology 17(10):897-900 
Sato H, Nakada S, Fujii T, Nakamura M, Suzuki-Kamata K (1999) Groundmass pargasite in the 1991-1995 dacite of Unzen volcano: phase stability experiments and volcanological implications. J Volcanol Geoth Res 89(1):197-212

Schmidt MW (1992) Amphibole composition in tonalite as a function of pressure: an experimental calibration of the Al-in-hornblende barometer. Contrib Mineral Petrol 110(2-3):304-310

Schmidt MW (1993) Phase relations and compositions in tonalite as a function of pressure: an experimental study at $650{ }^{\circ} \mathrm{C}$. Am J Sci 293:1011

Sillitoe RH (2010) Porphyry copper systems. Econ Geol 105(1):3-41

Sneeringer MA, Watson EB (1985) Milk cartons and ash cans: two unconventional welding techniques. Am Mineral 70:200-201

Spencer KJ, Lindsley DH (1981) A solution model for coexisting iron-titanium oxides. Am Mineral 66:1189-1201
Thomas W, Ernst WG (1990) The aluminum content of hornblende in calcalkaline granitic rocks; a mineralogic barometer calibrated experimentally to 12 kbars In: Spencer RJ, Chou I-M (eds) Fluid-mineral interactions: a tribute to H.P. Eugster. Geochem Soc Spec Publ 2:59-63

Tuttle OF, Bowen NL (1958) Origin of granite in the light of experimental studies in the system $\mathrm{NaAlSi}_{3} \mathrm{O}_{8}-\mathrm{KAlSi}_{3} \mathrm{O}_{8}-\mathrm{SiO}_{2}-\mathrm{H}_{2} \mathrm{O}$. Geol Soc Am Mem 74:153

Van Zalinge ME, Sparks RSJ, Cooper FJ, Condon DJ (in press) Early miocene large volume ignimbrites of the Oxaya formation, Central Andes. J Geol Soc London

Zen EA (1989) Plumbing the depths of batholiths. Am J Sci 289:1137-1157 